\title{
Final Technical Report on Award No. DE-FG02-92ER45465
}

This report summarizes the results and successes of the program including publications, personnel and collaborations.

\section{$\$ 1$ Motivation for the research}

The motivation of the previous program was to develop methods which could be used in a systematic study of the interface between glass and crystalline oxides. It was recognized that since the mechanical properties of glass-containing oxides are particularly important, it would be desirable to have a method which would also allow a systematic comparison of the mechanical properties of the materials. The reasoning behind the experimental approach of our previous program was as follows.

1. Grain boundaries which contain a layer of glass actually consist of two glass/crystal interfaces. These two interfaces may behave independently.

2. We can study the behavior of individual glass/crystal interfaces by depositing thin films on crystalline substrates. We then can control the composition of the glass layer.

3. We can compare the behavior of clean surfaces and interfaces with the behavior of similar interfaces which are in contact with glass films.

We found that the geometry of a glass film on a crystalline surface gave several new possibilities: we could develop methods for examining the mechanical properties of the films and the interfaces and we could examine both the crystallization of glass films and their wetting/dewetting behavior.

Another advantage of these specimen geometries is that the samples are amenable to examination by the characterization techniques which give information on the chemistry and structure over a wide range of length scales: both chemistry and crystallography can be controlled and changes monitored. We actually use SEM, AFM, TEM to examine the microstructure and local chemistry, VLM to obtain macroscopic views of the specimens, XRD to examine macroscopic crystallography of substrates and crystallized films, and RBS to quantify changes in the composition of glass bilayers.

\section{$\$ 2$ Background on Glass in Crystalline Ceramics}

Ceramic oxides are technologically important materials exhibiting a wide variety of properties. Interfaces play a crucial role in controlling the properties of these materials [1, 2]. Sintering is a common method for the processing of these ceramics. Sintering in the solid state is an energy-intensive method of processing because of the refractory nature of these materials. An alternate method involves the use of additives which form a liquid at relatively low temperatures and aid in the sintering process. The presence of the liquid phase allows for rapid mass transport which leads to rapid densification [3-5]. This process, referred to liquid-phase sintering (LPS), is therefore an attractive alternative to the conventional solid-state sintering processes. In LPS materials, the additives that are 


\section{DISCLAIMER}

This report was prepared as an account of work sponsored by an agency of the United States Government. Neither the United States Government nor any agency thereof, nor any of their employees, makes any warranty, express or implied, or assumes any legal liability or responsibility for the accuracy, completeness, or usefulness of any information, apparatus, product, or process diselosed, or represents that its use would not infringe privately owned rights. Reference herein to any specific commercial product, process, or service by trade name, trademart, manufacturer, or otherwise does not necessarily constitute or imply its endorsement, recom. mendation, or favoring by the United States Governmeat or any ageacy thereof. The views and opinions of authors expressed herein do not necessarily state or reflect those of the United States Government or any agency thereof. 


\section{DISCLAIMER}

Portions of this document may be illegible in electronic image products. Images are produced from the best available original document. 
used to form the liquid at the sintering temperatures (usually silicates) are distributed along the grain boundaries, triple junctions and multi-grain junctions [1, 5, 6]. While most of the grain boundaries are wet by the liquid, some of the boundaries are not. It is experimentally observed that low-energy boundaries (e.g., low-angle grain boundaries and twin boundaries) in polycrystalline alumina are not wet by the silicate liquid phase while higher- energy boundaries may have a continuous intergranular liquid film [6]. The thickness of the glass layer is reported to be dependent on the crystallography of the boundary for most oxide ceramics $[1,6]$ while it may be independent of crystallography for materials like $\mathrm{Si}_{3} \mathrm{~N}_{4}$ [7]. Although, there have been several theoretical analyses which rationalize the variations $[1,6,8]$ (or lack thereof) in the equilibrium thickness of the intergranular film, these interfaces are generally not well understood. On solidification, the resultant microstructure may contain a glassy phase along most grain boundaries. The width and distribution of the intergranular liquid phase also depends on the orientation of the bounding planes. The presence of the intergranular glassy phase affects the mechanical properties of the sintered material $[5,9,10]$. In spite of its importance, there is a lack of understanding of the relationship between structure, density and bonding at such interfaces and very limited work on the correlation between these factors and the properties of the material.

The properties of LPS materials depend not only on the distribution of the intergranular glass phase but also on the width of this layer although there is little direct information on this dependence. In oxide ceramics, it has been experimentally observed that different grain boundaries have a different thickness of the intergranular glass $[6,10,11]$. In $\mathrm{Al}_{2} \mathrm{O}_{3}$, for example, while some boundaries have thick intergranular films, some of the boundaries are essentially free of the intergranular glass $[1,6]$. Kinetics are slow at low temperatures so that the time required to attain thermodynamic equilibrium is long; annealing at higher temperatures allows the system to reach equilibrium at a faster rate at a given temperature. In the case of boundaries in which the absence of the glassy phase represents the lowest-energy configuration, the glass must be exuded from the boundary [12] while the liquid penetrates the boundary which favor the presence of an intergranular glass layer [13]. The relative magnitude of the different interfacial energies at the boundary and the free surface determine which situation will be preferred. Experimentally, the main approach has been to study the penetration of the liquid phase into polycrystalline ceramic bodies [13-17]. In this case, the liquid rapidly penetrates the high-angle boundaries and triple junctions to form a continuous liquid film at the boundaries. However, there is very little work on the reverse behavior, i.e., the migration of liquids out of low-energy boundaries $[18,19]$. Starting from an initial microstructure in which the intergranular glass has a thickness which is different from its equilibrium thickness, how does the system attain equilibrium? What are the relevant driving forces? What is the role of kinetics versus thermodynamics? These are some of the issues.that will be addressed in the proposed program. 
This discussion, of course, does not fully review the importance of glass in polycrystalline ceramics or even of glass in grain boundaries. For example, glass/crystal interfaces are important in glass/ceramic materials (ceramics produced by crystallizing glass bodies are forming). In refractories, glass corrodes polycrystalline ceramics by preferentially attacking (reacting at) grain boundaries.

\section{$\$ 3$ Selected highlights from this Award}

In this section, we will discuss some of the highlights of the previous program to give an indication of the quality of research that can be anticipated in the proposed program. Some preliminary work for the proposed program is presented in the following section. For ease of reading and reference, the illustrations are grouped together in $\$ 17$.

\section{Making bicrystals of alumina containing layers of glass}

PLD was used to produce amorphous interfacial layers, which were less than $0.5 \mu \mathrm{m}$ thick, between pieces of single-crystal $\mathrm{Al}_{2} \mathrm{O}_{3}$. A thin film of calcium-aluminosilicate glass could thus be deposited on the surface of a single piece of $\mathrm{Al}_{2} \mathrm{O}_{3}$ before bonding to create the bicrystal. The composition of the glass used is nominally $19 \mathrm{wt} \% \mathrm{CaO}, 41 \mathrm{wt} \%$ $\mathrm{Al}_{2} \mathrm{O}_{3}$ and 40 wt. $\% \mathrm{SiO}_{2}$. Starting powders of $\mathrm{CaCO}_{3}, \mathrm{Al}_{2} \mathrm{O}_{3}$, and $\mathrm{SiO}_{2}$ were mixed and then placed in a platinum crucible. The crucible was heated to $1600^{\circ} \mathrm{C}$, held at temperature for $24 \mathrm{~h}$ and then air-quenched to room temperature. The source of glass material in this case was a cylindrical section which had been cored from a larger piece obtained by pouring a similar composition out of a platinum crucible in the molten state. Using PLD, the composition of the glass could be preserved and the film thickness accurately controlled.

The bonding of the PLD-deposited samples was achieved using a vacuum furnace at $1980^{\circ} \mathrm{C}$ with a tungsten block providing a pressure of $12 \mathrm{kPa}$ at the interface as shown schematically in Figure 1a. The bicrystals were then cut into cross-sectional pieces, polished with diamond abrasives, and inspected with a visible-light microscope to determine the thickness of the glass layer. Cross-sectional specimens were then dimpled and ion-milled using our variable-speed rotating stage to minimize preferential thinning of the interfacial glass.

A bicrystal fabricated using this method is shown in Figure 1b. Here the two prismatic surfaces were aligned parallel with the $c$-axis of both grains parallel to the interface. The initial surface of the lower crystal is (1010) while that for the upper crystal is $(1120)$. The figure shows the layer of glass to be very thin $(<100 \mathrm{~nm})$ with both the (1010) and (1120) $\mathrm{Al}_{2} \mathrm{O}_{3}$ /glass interfaces exhibiting faceting. In this region the glass layer no longer appears continuous, and flat facets with (1010) planes in contact with the (1120) planes are observed. These flat contacts are separated by triangular pockets of glass bounded by (1011) and (1012) facets in the lower crystal, and the (1120) surface in the upper crystal. The upper (1120) $\mathrm{Al}_{2} \mathrm{O}_{3}$ /glass interface is also faceted, but appears wavy since it is not being viewed edge-on. 
It is possible that these regions of flattened contact do contain a thin amorphous film, as might be inferred from the diffuse-scattering dark-field image shown in Figure 1. In this type of image, the diffusely scattered intensity in the back-focal plane is used to form a dark-field image instead of using a reflection from either crystal. Since the amorphous material at the interface is responsible for the majority of the diffusely scattered intensity, the glassy phase will appear much brighter in the image that the crystal. Although bright lines are seen at the flattened contacts, the intensity of these lines is much lower that that from the glass pockets. It is well known that this type of image contrast can be misleading unless high-resolution images are also available. Such images were not obtained from these relatively thick samples.

The method described above is ideal for the study of the interaction of a liquid phase with specific $\mathrm{Al}_{2} \mathrm{O}_{3}$ surface orientations. The geometry used allows an $\mathrm{Al}_{2} \mathrm{O}_{3}$ surface to equilibrate in the presence of anorthite liquid without the influence of adjoining grains. $A$ near-anorthite composition was chosen such that the liquid would be in chemical equilibrium with $\mathrm{Al}_{2} \mathrm{O}_{3}$ at the annealing temperature. Finally, cross-sectional analysis in the TEM allows for direct observation of the $\mathrm{Al}_{2} \mathrm{O}_{3}$ /glass interface structure.

\section{Crystallizing glass}

Amorphous intergranular films are commonly observed in polycrystalline ceramics, and in many cases these films can control critical properties of the material [1]. The chemistry and structure of interfacial films may be manipulated by heat treatments. For example, $\mathrm{Al}_{2} \mathrm{O}_{3}$ ( $\alpha$ - or corundum structure) and $\mathrm{Si}_{3} \mathrm{~N}_{4}$-based ceramics often contain an amorphous intergranular phase which can be crystallized through post-sintering heat treatments in order to improve the high-temperature creep resistance of the materials $[10,11]$. To investigate the role which $\alpha-\mathrm{Al}_{2} \mathrm{O}_{3}$ grains play during the devitrification process, the crystallization of intergranular glass has been modeled by the deposition of thin glass. films on single-crystal $\mathrm{Al}_{2} \mathrm{O}_{3}$ substrates followed by heat treatments to devitrify the film.

The crystallization of anorthite glass on basal $\mathrm{Al}_{2} \mathrm{O}_{3}$ by in-situ heating in the TEM result in the epitactic growth of pseudo-orthorhombic (metastable) anorthite. Multivariant epitaxy can be seen in figure 2 . In this case a tricrystal junction has formed where all three orientational variants for the o-anorthite crystals meet at a single point. This can be seen at two locations in figure 2, where small A- and C-type grains appear as inclusions along a type-2 (bicrystal junction) interface between large grains. The wavy contrast seen in the type-A variant is typical of images formed using two-beam conditions with the $(3300)_{\mathrm{Al}_{2} \mathrm{O}_{3}} /(600)_{0 \text { nnor. }}$. This contrast is due to the network of misfit dislocations at the interface between the o-anorthite and the $\mathrm{Al}_{2} \mathrm{O}_{3}$.

The anorthite-glass film completely crystallizes as the pseudo-orthorhombic phase. The epitaxy of this framework-silicate structure on a corundum-structure oxide is an example of epitaxy between structurally dissimilar materials. A special dislocation network gives a stable interface structure between the two materials which does not contain any residual amorphous material [20]. 


\section{Penetration of glass through a dense polycrystalline $\mathrm{MgO}$}

The first stage of LPS involves the formation of a liquid and its redistribution within the green compact [5]. This process is driven by a reduction of the free energy associated with the replacement of $S / S$ or $S / V$ interfaces by $S / L$ and $L / V$ interfaces. This redistribution depends on the crystallography of the boundary because the $S / S$ boundary energies depend on the boundary orientation. The penetration of liquid into dense, polycrystalline compacts can shed light on the processes occurring during the first stage of LPS $[21,22]$. This study is the thin-film analog of the bulk penetration experiment [13, 14].

The thin-film approach developed in our program can provide new insights on the initial stages of solid-liquid interaction during infiltration. Thin $\mathrm{MgO}$ disks $(3 \mathrm{~mm}$ in diameter, $\sim 10 \mu \mathrm{m}$ thickness) were infiltrated with monticellite glass at $1700^{\circ} \mathrm{C}$ for $2 \mathrm{~min}$. Figure 3 is an AFM image showing a triple junction on the bottom surface of the specimen. The glass has dewet most of this surface and the remainder has probably crystallized on cooling. There is a noticeable depression at the center of the silicate island. This observation, coupled with complementary SEM observations leads to the conclusion that the liquid penetrates the thin sample completely and wets the bottom surface at the annealing temperature. The glass dewets the surface as $T$ is lowered by being drawn back into the triple junctions. Some glass remains in the grain boundary surface grooves but the dewetting is clearly dominated by the triple junctions.

\section{Glass droplets on alumina surfaces}

The surface energy of a liquid is isotropic (independent of orientation) and hence a liquid droplet assumes a spherical shape to minimize the total surface energy of the system. For a liquid droplet on a flat, isotropic substrate, the shape corresponding to the minimum in energy can be described as a spherical cap (appearing circular in plan view). The presence of a surface structure (ledges, for instance) can alter the shape of the liquid droplet.

The equilibrium shape of a solid is geometrically similar to the shape obtained from the Wulff construction or the polar plot of the surface energy (the $\gamma$-plot). Surfaces that appear in the Wulff shape are those with the lowest energy. Herring's theorem states that any surface which is not a part of the Wulff shape (high-index, higher-energy planes) will reconstruct into a hill-and-valley structure comprising the low-energy facets; edge effects are neglected. The reconstruction of high-index surfaces of $\mathrm{Al}_{2} \mathrm{O}_{3}$ is well known [23, 24]. In particular, the faceting of $\{1010\}$ (the first-order $(\mathrm{m})$ prism plane) of $\mathrm{Al}_{2} \mathrm{O}_{3}$ has been studied in great detail. This plane is unstable and can reconstruct into $\{1011\}$ and $\{1012\}$ facets, which intersect along a $<1210>$ direction.

When the length scale of faceting is of the order of the size of the droplets on the surface, interesting types of solid-liquid interactions take place. An FESEM operating at low voltages $(\sim 5 \mathrm{kV})$ provides suitable resolution for studying these interactions. 
Figure 4a is an $\mathrm{SE}$ image of a dewet droplet on the m-plane of $\mathrm{Al}_{2} \mathrm{O}_{3}$. The sample was annealed at $1700^{\circ} \mathrm{C}$ for $7 \mathrm{~h}$. The faceting of the substrate surface is seen clearly. The height of the facets is of the order of tens of nanometers. The facets intersect along a $<11 \overline{2} 0\rangle$ direction, i.e., the straight lines that are seen are parallel to this direction. In the plan view, the liquid droplet is not circular in this case. The facets on the surface are also affected by the presence of the liquid, bending and separating into microfacets which in turn also facet. The glass pocket is flattened on one side indicating that the liquid preferentially wets one type of facet in the stepped structure. The faceting behavior of the alumina surface in the presence of glass has been studied earlier. The liquid preferentially wets one type of facet on the surface. The steps bending is particularly striking in the vicinity of the solid/liquid/vapor (SLV) triple-junction.

Figure $4 \mathrm{~b}$ is an SE image from a sample heat treated at $1695^{\circ} \mathrm{C}$ and cooled very slowly $\left(1^{\circ} \mathrm{C} / \mathrm{min}\right)$ in the furnace. It shows the detailed morphology of the interaction of liquid with the steps and may be closer to the equilibrium morphology of the droplet. There is significant spreading of the droplet along one type of facet indicating that the wetting behavior is very different on the two types of facets that are present on the reconstructed $m$-plane. The liquid is again seen to wet one kind of facet in the stepped structure preferentially. Microfaceting of the facet which is wet by the liquid is also clearly seen through the liquid. This observation clearly illustrates the influence of crystallography on the wetting behavior.

5 Evaporation from surfaces in the presence of silicate liquid

Since ceramic materials are processed at high temperatures, different mechanisms of mass transport will be operative. The LPS process involves the formation of a silicate liquid at the sintering temperature. In this case, mass transport takes place at the solidliquid, solid-vapor and liquid-solid interfaces and the mechanism and kinetics of these processes controls the resulting microstructure. The silicate phase, which is usually the sintering additive, also influences the evaporation/vaporization from the ceramic. The importance of the evaporation process has been clearly brought out in our studies on the dewetting of anorthite and celsian on $\mathrm{Al}_{2} \mathrm{O}_{3}$ substrate.

We used PLD to deposit thin films $(\sim 100 \mathrm{~nm})$ of celsian $\left(\mathrm{BaAl}_{2} \mathrm{Si}_{2} \mathrm{O}_{8}\right)$ on $\mathrm{Al}_{2} \mathrm{O}_{3}$ singlecrystals of basal orientation. The film/substrate assembly were then annealed in a vacuum furnace at higher temperatures $\left(1750^{\circ} \mathrm{C}\right.$ to $\left.1850^{\circ} \mathrm{C}\right)$ than was necessary to achieve a similar effect for anorthite glass. The surface of the heat-treated samples was characterized using the FESEM (Hitachi S900) operating at $5 \mathrm{kV}$.

A secondary-electron (SE) image from a sample annealed at $1770^{\circ} \mathrm{C}$ for $10 \mathrm{~min}$ is shown in Figure 5a. Evaporation takes place from the $\mathrm{Al}_{2} \mathrm{O}_{3}$ surface at these temperatures. The three-fold symmetry of the $\mathrm{Al}_{2} \mathrm{O}_{3}$ substrate is evident from the morphology seen on the substrate. A polyhedral particle of the crystallized celsian phase is seen in the middle. Crystalline celsian is monoclinic at normal temperatures and pressure. However, a metastable form of celsian (hexacelsian) also exists. From the morphology of the particle, 
it may be concluded that the hexagonal form of celsian has crystallized on the substrate. It is not uncommon for a metastable phase to form because of the nucleation advantage (lower interfacial energy with the substrate). The particle on the substrate acts as a barrier for evaporation which is evident from the succession of plateaus which increase in height as we move towards the particle.

A second SE image from a sample annealed at $1850^{\circ} \mathrm{C}$ for $2 \mathrm{~h}$ is shown in Figure $5 \mathrm{~b}$. The near-hexagonal region seen in the middle is the initial position of the celsian particle which has fully evaporated in this case. The evaporation from the basal surface of $\mathrm{Al}_{2} \mathrm{O}_{3}$ takes place by the removal of atoms from the step sites causing the steps to move. When the steps encounter an obstacle, they are pinned and have to bow around the obstacle. The steps around the crystallized celsian particles bend significantly in the present case. The presence of the silicate phase clearly affects the evaporation from the $\mathrm{Al}_{2} \mathrm{O}_{3}$ substrate.

6 Mechanical properties of glass films

Mechanical properties of alumina-based ceramics are of great industrial importance and often determine the utility of these materials for many engineering applications. The fabrication of such materials using LPS usually leads to the incorporation of silica-based sintering aids at the grain boundaries [25]. The presence of these intergranular phases strongly influences mechanical properties of the ceramic material, in particular, its strength, plastic deformation, etc. [26, 27]. In order to understand the interaction between the glass layer and the crystalline grains at a fundamental level, the amorphous material can be placed in contact with the ceramic substrate as a thin film in a controlled manner . In our work on this topic, the mechanical properties of the silicate/ $\mathrm{Al}_{2} \mathrm{O}_{3}$ interfaces have been tested by continuous nanoindentation . In order to model such interfaces, thin silicate films of pre-determined composition were grown on single-crystal $\alpha$-alumina substrates of (0001) orientation. The glass composition of interest in this work is one frequently observed at the grain boundaries of polycrystalline $\mathrm{Al}_{2} \mathrm{O}_{3}$, namely $\mathrm{CaAl}_{2} \mathrm{Si}_{2} \mathrm{O}_{8}$ (anorthite). $\mathrm{The} \mathrm{Al}_{2} \mathrm{O}_{3}$ substrates were elastically strained prior to and during deposition of silicate films. Both tensile and compressive stresses were applied, with care being take to assure that the stresses never exceeded the elastic limit to the substrate. Figure $6 a$ is a surface plot SPM/indenter image of crystallized, dewet, film on the (0001) surface of $\mathrm{Al}_{2} \mathrm{O}_{3}$. The advantage of using the Hysitron indenter device is that the indenter can be positioned precisely over the area of interest and the same regions can be imaged before and after indentation (see Figures $6 \mathrm{~b}$ and $6 \mathrm{c}$ ).

Comparison of the indentation load-displacement data collected for films deposited onto $\mathrm{Al}_{2} \mathrm{O}_{3}$ substrates of different orientations can be seen on Figure $6 \mathrm{~d}$. Shown on Figure $6 \mathrm{e}$ are the load-displacement data produced by indenting strained silicate films grown on substrates strained to $-0.4 \mathrm{GPa}, 0$ (unstrained) and $+0.4 \mathrm{GPa}$, respectively. It can be seen that change in sign of the residual stress (compression or tension) in a film produces measurable changes in the mechanical responses as shown in the indentation curves. The data show that tensile stress in the film enhances indentation plasticity during the initial 
stages of deformation, producing larger indents and a lower measured hardness. Compressive stress in the film increases apparent hardness by decreasing the shear stresses beneath the indenter. Remarkably, the results of indenting films with residual stresses produced after their substrates strained to $\pm 1 \mathrm{GPa}$ have been unloaded show that such stress levels did not cause significant changes in the mechanical response of the films. Instead, the resulting values of the film's maximum indentation depth and residual plastic deformation on originally strained substrates are approaching those of unstrained ones.

Those irregularities in load-displacement data are related to the changes in surface morphology of the films. Increasing stress produced induced permanent deformation (microcracking and film delamination) in the silicate film [28], as a result of the film's failure to accommodate non-uniform compressive or tensile stresses imposed after substrate unloading.

* The following two sections illustrate our work on characterizing the surface of the starting single crystals. It was particularly important, for example, to know that the $\{1010\} \mathrm{Al}_{2} \mathrm{O}_{3}$ surface is intrinsically unstable; faceting of the $\{1010\}_{\mathrm{Al}_{2} \mathrm{O}_{3}}$ /glass interface is not then due to the glass but the kinetics may be enhanced by the presence of the glass.

\section{Reconstruction of the surface of alumina}

Faceting, or the decomposition of a crystal face into several surfaces of different crystallographic orientation, can occur in ceramic materials at elevated temperatures. This process may take place during crystal growth, crystal evaporation, or deposition of thin films on single-crystal ceramic substrates. The latter is the motivation of the present research. Due to its chemical inertness, high melting point and the availability of large single crystals, $\mathrm{Al}_{2} \mathrm{O}_{3}$ is widely used as a substrate for thin-film growth. The structure of the substrate surface is one of the factors that determine the shape and mechanical properties of the interface between the film and the substrate. Characterization of the surface of the substrate, therefore, is the first step in understanding high-quality films and coatings.

Work on understanding the fundamentals of why and how a surface facets has been going on for a century [29]. The first attempt to understand how faceted surface structures form from an originally smooth surface was made by Mullins [30]. By considering observations of the faceting of metal surfaces, Mullins realized that surface faceting begins with the nucleation and growth of an individual facet [30]. For his model, Mullins used the growth of an isolated linear facet which consists of a simple plane (a flat facet having a low surface energy) and a complex side (a curved surface with no corresponding crystallographic plane). Our work on the faceting of the alumina m-plane surface directly demonstrates the validity of Mullins model [23]. The calculations made in this model yield the possible shapes of the facet as a function of time and in terms of basic physical parameter of the solid. Mullins predicted that the facets should grow at a constant velocity. This prediction was made for the growth rate of relatively large facets and, 
generally, may not hold true for facet nucleation or for growth of small (monatomic) facets.

In our work, faceting of low-index surfaces of $\mathrm{Al}_{2} \mathrm{O}_{3}$ was studied ex situ by SPM and SEM. Polished single-crystal substrates were annealed in air at $1400^{\circ} \mathrm{C}$ for 8 hours. Since structurally, $\mathrm{Al}_{2} \mathrm{O}_{3}\left(\alpha-\mathrm{Al}_{2} \mathrm{O}_{3}\right.$, i.e., corundum) is formed by oxygen anions in a pseudohexagonal close packed array with two thirds of the octahedral interstices filled by aluminum cations, thermodynamic and structural considerations, cause the (0001) surface of $\mathrm{Al}_{2} \mathrm{O}_{3}$ to be stable. Therefore, it is not expected to undergo faceting, while the $\{1010\}$ surface of $\mathrm{Al}_{2} \mathrm{O}_{3}$ is found to be unstable and to reconstruct upon heat-treatment. Since ceramic substrates are usually prepared by cutting and polishing of single crystals, the substrate surfaces are usually slightly vicinal (i.e., slightly tilted away from the nominal orientation). To accommodate the misorientation between the polished surface and the lattice plane, such surfaces are expected to attain terrace-and-step morphology when annealed at elevated temperatures. This is the driving force behind the reconstruction of polished single-crystal surfaces of stable orientation [31]. Thus, the (0001) surface of alumina reconstructs upon annealing into terraces of the (0001) orientation which are bound by steps aligned along the [1210] direction in the crystal. Reconstruction of the (0001) surface begins with formation of $\sim 0.2 \mathrm{~nm}$ (or one-sixth of the hexagonal unit-cell $\mathrm{c}$ lattice parameter) high steps which tend to exist as pairs, giving $0.4 \mathrm{~nm}$ high steps. With increased heat-treatment times, the steps coalesce into facets which are typically multiples of unit-cell parameter in height. Such facet coarsening is accompanied by an increased surface area of the terraces.

In contrast to the (0001) surface, the high-temperature faceting of the $\{1010\}$ surface of $\mathrm{Al}_{2} \mathrm{O}_{3}$ proceeds through its breakdown into the $\{1012\}$ and $\{1011\}$ planes (hill-andvalley morphology, see Figure 7). Since such reconstruction is driven by thermodynamic requirements, it is expected that the $\{1012\}$ and $\{1011\}$ facets have lower energies than the original $\{1010\}$ surface. The progression of faceting of the (1010) surface starts with nucleation and growth of a single facet. The growth of this facet perturbs the local surface structure and promotes nucleation of collinear facets in the close vicinity of the original one. Through time, these facets coarsen into the final hill-and-valley morphology.

8 The (001) surface of spinel

The kinetics of step motion on vicinal surfaces is a fundamental concept in surface science. In ceramic materials, most surface processes, such as reconstruction and step motion occur at high temperature, which eliminates the possibility of in situ observations. However, the dynamics of surface behavior must be understood to explain the surface morphologies of many materials, such as thin ceramic films, which are grown under nonequilibrium conditions. This part of our work has examined step motion on the (001) surface of $\mathrm{MgAl}_{2} \mathrm{O}_{4}$ spinel at high temperatures.

In the normal spinel structure, oxygen anions can be thought as forming a face-centered cubic (fcc) sublattice while $\mathrm{Mg}^{2+}$ cations occupy $1 / 8$ of the tetrahedral interstices, and $\mathrm{Al}^{3+}$ 
cations occupy $1 / 2$ of the octahedral interstices. From electrostatic and thermodynamic considerations, the $\{001\}$ surface is expected to be the stable termination of the spinel crystal [32]. Indeed, upon annealing at $1000-2000^{\circ} \mathrm{C}$, the polished (001) surface of $\mathrm{MgAl}_{2} \mathrm{O}_{4}$ spinel reconstructs to the terrace-and-step geometry [33]. At sub-evaporation temperatures $\left(1200-1600^{\circ} \mathrm{C}\right)$, the surface morphology is dominated by single $(\sim 2-\AA$ high) steps. The single steps move and align preferentially along either $<110\rangle$ or $<1 \overline{10}$ directions of the crystal. The steps which are separated by $\sim 4.0 \AA$ (or by even multiples of $\sim 2.0 \AA$ ) have the same preferred direction of alignment/motion, while the steps separated by $\sim 2.0 \AA$ (or by odd multiples of $\sim 2.0 \AA$ ) are aligned perpendicular to one another and move in the orthogonal directions.

At temperatures where surface evaporation takes place $\left(z 1800^{\circ} \mathrm{C}\right)$, the high velocities of step motion make it possible for the single steps to associate into stable step pairs (double steps). The mechanism of formation of a double step is as follows: when the lower step, which rapidly moves along the $<110>$ direction, is blocked by the upper step, which moves slowly along the $\langle 110\rangle$ direction but rapidly along the $<110\rangle$ direction, step pileup occurs. This pileup results in formation of a $4-\AA$-high double step. The directions of motion and alignment of such a double step is then determined by the attached upper single step. As long as the lower steps moves faster than the upper steps, the double ( 4 $\AA$-high) steps are stable and may move as single entities along the surface, and, like single steps, align along either $\langle 110\rangle$ or $\langle 110\rangle$ directions. The reverse process, the dissociation of double steps, occurs when the double steps encounter obstacles in the course of their motion, such as trains of steps moving in the perpendicular direction or crystal defects.

Anisotropic motion of the steps on the $\{001\}$ surface of $\mathrm{MgAl}_{2} \mathrm{O}_{4}$ also manifests itself in the unusual pseudo-fourfold symmetry and double-spiral structure of the evaporation patterns formed at the dislocation termination sites [34] (see Figure 8). Here, the evaporation spiral created at the site of an emerging dislocation is formed through rotation of not one but two $\sim 2.0 \AA$-high half-ledges, which are aligned orthogonally to one another. The ledges bundle together to form double steps at spiral sides and separate into $\sim 2.0 \AA$ steps in spiral corners. It is expected that the anisotropic growth/evaporation and alignment of the steps on the $\{001\}$ surface of $\mathrm{MgAl}_{2} \mathrm{O}_{4}$ is related to the existence of special "filled" directions in the (001) crystal planes in the spinel structure [33]. For each \{001\} plane, there is only one such direction (which may be either the $<110\rangle$ or the $<110>$ one). As a result, the $\{001\}$ spinel surface may exist as two possible surface variants: one with the $\langle 110\rangle$ preferred direction of growth, and another with the $\langle 110\rangle$ one. Such domains separated by $\sim 2.0 \AA$ and $\sim 4.0 \AA$ steps are the main structural constituents of the reconstructed $\{001\}$ surface of the $\mathrm{MgAl}_{2} \mathrm{O}_{4}[33]$.

9 Exuding glass from grain boundaries in alumina

LPS is an attractive route for the processing of ceramics because it gives enhanced densification rates at relatively low temperatures. The liquid phase which forms at high 
temperatures and aids in densification may be retained as an intergranular phase at low temperatures. This intergranular layer can then affect the mechanical and electrical properties of the sintered product [6]. A subsequent treatment may be required to optimize properties. The post-fabrication treatment may be used to crystallize the grainboundary glass or to eliminate it from the grain boundaries by exuding it to the surface. It is also possible to use a fugitive sintering aid (e.g., $\mathrm{LiF}$ in spinel) which volatilizes during or after sintering [35]. In general, it is not possible to crystallize the glassy phase completely [36], so the exudation of the liquid phase is an important alternative.

There have been few systematic studies of the elimination of the grain-boundary liquid by its migration to the free surface. The process has been reported to occur in cases where highly reducing conditions were used. The elimination of yttrium-aluminum oxide from polycrystalline AIN under reducing conditions was demonstrated by Ueno and Horiguchi [18], Drennan et al. showed the migration of the liquid phase to the free surface during the sintering of $\mathrm{Mg}$-PSZ with $\mathrm{SrO}$ and $\mathrm{SiO}_{2}$ additions. We have now . established that it is possible to exude the silicate liquid from bicrystal boundaries in $\mathrm{Al}_{2} \mathrm{O}_{3}$.

Figure 9 is an SE image of a cc bicrystal (c planes adjoining) annealed at $1650^{\circ} \mathrm{C}$ for $2 \mathrm{~h}$. The boundary is at the center (running from top to bottom). The liquid that has migrated out of the boundary can be seen as droplets on either side of the boundary. The SE contrast is different for droplets on either side of the boundary due to differences in the contact angle (and thus the surface curvature) of the droplets on the surface. The droplets on one side of the boundary (right) appear more rounded indicating that the wetting tendency on this side may be lower than on the left side of the boundary. The morphology of the dewet droplets depends upon the surface energy and the crystallography of the surface. The liquid which forms in the boundary at the annealing temperature is exuded from the boundary and spreads along the free surface. On cooling the sample, the liquid dewets the surface forming droplets on the surface. The schematic inset shows the initial state (left) of the bicrystal and the final state (right) of the dewet droplets on the surface caused by the annealing treatment. The dewetting behavior is similar to that reported for continuous liquid films of silicate liquids on $\mathrm{Al}_{2} \mathrm{O}_{3}$ surfaces . It is also observed that the average size of the droplets is smaller at larger distances from the boundary indicating that the thickness of the liquid layer is smaller at larger distances. from the boundary. The apparent width of the boundary in Figure 9 is larger than the thickness of the glass layer because grain-boundary grooving has occurred. The bright lines in the SE image of the boundary are due to the enhanced generation of secondary electrons from regions having a small radius of curvature. 


\section{\$4 Publications Generated by this Award ('92-'00)}

Copies of the selected publications are included with this proposal as an appendix to illustrate the type of research which has been carried out with previous support from DoE. (J: journal, C: conference proceedings, S: submitted or in press, B: Book Chapter) Book Chapters

A3 Farrer, J.K., Carter, C.B. and Michael, J., 2000 (Fall) in "Fundamentals of Electron Backscatter Diffraction with Applications of Orientation Microscopy" (Plenum, New York) "EBSP of Ceramics". Journal papers

J180 Heffelfinger, J.R., Bench, M.W. and Carter, C.B., 1995, Surf. Sci. 343 L1161-L1166. "On the Faceting of Ceramic Surfaces."

J181 Ramamurthy, S., Hebert, B.C. and Carter, C.B., 1995, Phil. Mag. Lett. 72 (5), 269-275. "Dewetting of Glass-Coated $\alpha-\mathrm{Al}_{2} \mathrm{O}_{3}\{100\}$ Surface."

J182 . Ramamurthy, S., Mallamaci, M.P. and Carter, C.B., 1996, Scripta Met. 34 (11), 1179-1783. "Initial Stages of Solid-Liquid Interactions in the $\mathrm{MgO}^{-\mathrm{CaMgSiO}} 4$ System."

J185 Ramamurthy, S., Mallamaci, M.P., Zimmerman, C.M., Carter, C.B., Duncombe, P.R. and Shaw, T.M., 1996, JMSA 2 (3), 113-128. (reprinted in Microscopy \& Microanalysis 3 suppl. 3) "Microstructure of Polycrystalline MgO Penetrated by a Silicate Liquid."

J189 Heffelfinger, J.R., Bench, M.W. and Carter, C.B., 1997, Surf. Sci. 370, L168-L172. "Steps and the Structure of the (0001) a-Alumina Surface."

J193 Heffelfinger, J.R. and Carter, C.B., 1997, Phil. Mag. Lett., 76 (3), 223-232 "The Effect of Surface Structure on the Growth of Ceramic Thin Films."

J194 Heffelfinger, J.R. and Carter, C.B., 1997, Surf. Sci. 389 188-200 "Mechanisms of Surface Faceting and Coarsening."

J197 Zagrebelny, A. and Carter, C.B., 1997, Scripta Met. 37 1869-75 "Indentation of Strained Silicate-Glass Films on Alumina Substrates."

J198 Mallamaci, M.P., Bentley, J. and Carter, C.B., 1997, Acta Materialia 46 283-303 "In-Situ TEM Crystallization of Silicate-Glass Films $\mathrm{Al}_{2} \mathrm{O}_{3}$."

J199 Mallamaci, M.P., Sartain, K.B. and Carter, C.B., 1998, Phil. Mag. 77 562-575, "Crystallization of Calcium-Hexaluminate on Basal Alumina."

J201 Ramamurthy, S. and Carter, C.B., 1998, phys. stat. sol. (a) 166 37-55 "The $\{111\} /\{100\}$ Interface in Cubic Materials and Related Materials."

J204 Mallamaci, M.P. and Carter, C.B., 1998, Acta Mater. 46 2895-2907, "Faceting of the Interface between $\mathrm{Al}_{2} \mathrm{O}_{3}$ and Anorthite Glass."

J208 Mallamaci, M.P. and Carter, C.B., 1999, J. Am. Ceram. Soc. 82 (1) 33-42, "Crystallization of Pseudo-Orthorhombic Anorthite on Basal Sapphire."

J210 Zagrebelny, A.V. and Carter, C.B., 1999, Phil. Mag. A 79 835-845, "Detection of Residual Stresses in Glass-Penetrated Polycrystalline Alumina with Nanoindentation."

J213 Zagrebelny, A., Lilleodden, E., Gerberich, W. and Carter, C.B., 1999, J. Am. Ceram. Soc. 82 (7) $1803-08$, "Indentation of Silicate-glass Films on $\mathrm{Al}_{2} \mathrm{O}_{3}$ Substrate"

J221 Ravishankar, N. and Carter, C.B., 2000, Interface Sci., 8(2/3), 297-306, "Glass/Crystal Interfaces in Liquid-Phase Sintered Materials."

J222 Ramamurthy, S., Schmalzried, H. and Carter, C.B., 2000, Phil. Mag. A, 80, 26512674, "Interaction of Silicate Liquid with a Sapphire Surface."

Conference Proceedings

C225 Mallamaci, M.P., Ramamurthy, S. and Carter, C.B., 1994, Mat. Res. Soc. Symp. Proc. 318 589-594, "Liquid Infiltration of $\mathrm{MgO}$ and $\mathrm{Al}_{2} \mathrm{O}_{3}$ Thin Films." 
C227 Ramamurthy, S., Mallamaci, M.P. and Carter, C.B., 1994, Mat. Res. Soc. Symp. Proc. 321 633-638, "Crystallization of Glass Films on Single-Crystal MgO Substrates."

C229 King, S.L., Heffelfinger, J.R., Mallamaci, M.P., McKernan, S. and Carter, C.B., 1994, Mat. Res. Soc. Symp. Proc. 318 407-412, "Surface Steps on (100) MgO Substrates Imaged by TEM, SEM and AFM."

C233 Bentley, J., Horton, L.L., McHargue, C., McKernan, S., Carter, C.B., Tanaka, S. and Davis, R.F., 1994, Mat. Res. Soc. Symp. Proc. 332 385-391, “Compositions and Chemical Bonding in Ceramics by Quantitative Electron Energy-Loss Spectrometry."

C243 McKernan, S. and Carter, C.B., 1994, 52nd Annual Meeting MSA, New Orleans, 420-421, "Convergent-Beam Thickness Determination: The Advantages of Digital Imaging."

C245 Mallamaci, M. and Carter, C.B., 1994, ICEM 13 Paris, France. "Nucleation and Growth of Orthorhombic Anorthite."

C246 Mallamaci, M.P., Sartain, K.B. and Carter, C.B., 1994, ICEM 13 Paris, France, "Glass in Aluminum-Oxide Grain Boundaries."

C247 Ramamurthy, S., Mallamaci, M.P. and Carter, C.B., 1994, 28th Meeting MAS, New Orleans, 193-194, "Chemistry of Intergranular Films in MgO."

C248 Ramamurthy, S. and Carter, C.B., 1994, 52nd Annual Meeting MSA, New Orleans, 359-360, "The $\{111\} /\{100\}$ Interface in Cubic Materials."

C250 McKernan, S., King, S.L. and Carter, C.B. 1994, ICEM 13 Paris, France, 891, "Convergent-Beam Thickness Determination: A Quantitative Comparison of Recording Media."

C25s Heffelfinger, J.R., Bench, M.W. and Carter, C.B., 1995, 53rd Annual Meeting MSA, Kansas City, 332-333, "AFM Studies of Annealed Single-Crystal aAlumina Surfaces."

C257 Bench, M.W., Heffelfinger, J.R. and Carter, C.B., 1995, 53rd Annual Meeting MSA, Kansas City, 334-335, " AFM Study of the Dynamics of $\alpha$-Alumina Surface Faceting During High-Temperature Processing."

C258 Ramamurthy, S., Hebert, B.C. and Carter, C.B., 1995, 53rd Annual Meeting MSA, Kansas City, 340-341, "Non-Equilibrium Silicate Glass in Contact with Faceted $\{1010\} \alpha-\mathrm{Al}_{2} \mathrm{O}_{3}$ Surface: An SEM Study."

C259 Ramamurthy, S., Hebert, B.C. and Carter, C.B., 1995, 53rd Annual Meeting MSA, Kansas City, 342-343, "Olivine-MgO Interfaces Produced by Crystallization of Glass Films on Single-Crystal MgO Substrates."

C260 Ramamurthy, S., Mallamaci, M.P., Zimmerman, C.M., Sartain, K.B. and Carter, C.B., 1995, IIBM-7, Lisbon, Portugal, Materials Science Forum 207-209 (2), 753-756, "Glass Crystallization and Interfaces."

C265 Zagrebelny, A.V., Nelson, J.C., Lilleodden, E.T., Ramamurthy, S. and Carter, C.B., 1996, Mat. Res. Soc. Symp. Proc. 401, 103-108, "Alumina-Silicate Glass Interfacial Properties Probed by Micromechanical Testing Techniques."

C266 Heffelfinger, J.R., Bench, M.W. and Carter, C.B., 1996, Mat. Res. Soc. Symp. Proc. 399, 263-268, "On the Roughening of Ceramic Surfaces.".

C268 Ramamurthy, S., Hebert, B.C., Carter, C.B. and Schmalzried, H., 1996, Mat. Res. Soc. Symp. Proc. 398, 295-300, "Interaction of Silicate Liquid with Sapphire Surfaces."

C269 Zagrebelny, A.V., Nelson, J.C., Ramamurthy, S., and Carter, C.B., 1996, Microscopy \& Microanalysis 996, Minneapolis, 662-663, "SilicateGlass/Sapphire Interfaces Probed with Micromechanical Testing Instruments: SEM and TEM Combined Characterization."

c270 Zagrebelny, A.V., Lilleodden, E.T., Nelson, J.C., Ramamurthy, S., and Carter, C.B., 1996, Microscopy \& Microanalysis '96, Minneapolis, 660-661, "In-situ and Exsitu AFM Imaging of $\mu \mathrm{N}$ Load Indents on Silicate Glass/Alumina Interfaces." 
C272 Heffelfinger, J.R., Bench, M.W., Johnson, M.T., and Carter, C.B., 1996, Microscopy \& Microanalysis '96, Minneapolis, 368-369, “AFM as a Tool for Studying Ceramic Surfaces."

C276 Carter, C.B., Heffelfinger, J.R. and Ramamurthy, S., 1996, Acta Microscopica 5B, 4-5, "Interaction between Glass and Surfaces: A Combined AFM, SEM, TEM Study."

c277 Lilleodden, E.T., Zagrebelny, A.V., Ramamurthy, S. and Carter, C. B., 1996, Mat. Res. Soc. Symp. Proc. 436, 177-182, "Probing Silicate/Sapphire Interfaces using AFM and Nanoindentation."

C278 Zagrebelny A.V., Lilleodden E. T., Carter C. B., 1996, Mat. Res. Soc. Symp. Proc., 458, 179-184, "Effect of Glass Composition on Mechanical Properties of Interfaces between Alumina and Silicate Glass."

C279 Zagrebelny, A.V., Nelson, J.C. and Carter, C.B., 1996, Mat. Res. Soc. Symp. Proc., 440, 189-194, "Micromechanical Deformation of Single-Crystal Alumina Surfaces.".

C284 Yanina, S. V., Johnson, M.T. and Carter, C. B., 1997, Microscopy and Microanalysis, 3 Suppl. 2, 741-742, "The Dynamics of MgO Surface Faceting."

C285 Zagrebelny, A.V. and C. B. Carter, 1997, Microscopy and Microanalysis, 3 Suppl. 2, 1269-1270, "Micromechanical Behavior of Silicate Glass Films on Alumina Substrates."

C286 Zagrebelny, A.V. and C. B. Carter, 1997, Microscopy and Microanalysis, 3 Suppl. 2, 1281-1282, "Surface Morphology of Mechanically Strained Silicate Glass Films on Alumina Substrates."

C294Carter, C.B., 1998, Microscopy and Microanalysis, 4 Suppl. 2, 550-551, "Dislocations in Ceramics."

C295 Yanina., S.V., Johnson, M.T., Z. Mao and Carter, C.B., 1998, Microscopy and Microanalysis, 4 Suppl. 2, 590-591, "Devitrification of Monticellite (CaMgSiO 4$)$ Films Grown on (001)-Oriented Single-Crystal MgO."

C296 Mao, Z., Johnson, M.T. and Carter, C.B., 1998, Microscopy and Microanalysis, 4 Suppl. 2, 592-3, "Defects in Pseudo-Orthorhombic Anorthite on Basal Sapphire."

C308 Ramamurthy, S., Mallamaci, M.P. and Carter, C.B., 1998; Proc. EUREM-11, (Dublin 1996), 2 706-707, "Microstructures Between Calcium Aluminosilicate and $\alpha-\mathrm{Al}_{2} \mathrm{O}_{3}$."

C312 Zagrebelny, A.V. and Carter, C.B., 1998, Mat. Res. Soc. Symp. Proc. 505, 481-486, "Micromechanical Properties of Silicate-Glass Films on Sapphire Substrates."

C315 Carter, C.B., Ravishankar, N., Korte, C and Mallamaci, M.P., 1999 Microscopy and Microanalysis, 5 Suppl. 2, 98-99, "Interfaces in Glass-Containing Ceramics."

C320 Ravishankar, N. and Carter, C.B., 1999, Microscopy and Microanalysis, 5 Suppl. 2, 800-801 "Migration of Silicate Liquid Out of Grain Boundaries in Ceramics."

C321 Ravishankar, N., Schmalzried, H. and Carter, C.B., 1999, Microscopy and Microanalysis, 5 Suppl. 2, 811-812 "Wetting of Anorthite Liquid on m-Sapphire Substrates."

c325 Carter, C.B., Ravishankar, N. and Yanina, S.V., 1999, Inst. Phys. Conf. Ser. 161, 43-46 (EMAG99 Sheffield) "Dewetting Behaviour of Reactive Silicate Glass Films on Single-Crystal Ceramic Substrates."

C326 Ravishankar, N. and Carter, C.B., 1999, Revista Latinoameriacana de Metalurgia y Materiales 19 7-12, CIASEM, Venezuela 24-28 October 99, "Application of SEM to the Study of Ceramic Surfaces".

C328 Ravishankar, N. and Carter, C.B., 2000, Microscopy and Microanalysis, 6 Suppl. 2, 388-9, "Silicate Glass and Evaporation from Sapphire Surfaces".

C329 Ravishankar, N., Johnson, M.T. and Carter, C.B., 2000, Microscopy and Microanalysis, 6 Suppl. 2, 386-7, "Migrating Interfaces in Sapphire Bicrystals and Tricrystals". 
Yanina, S.V. and Carter, C.B., 2000, Microscopy and Microanalysis, 6 Suppl. 2, 714-5, "Evaporation Spirals on $\{111\}$ and $\{001\}$ surfaces of $\mathrm{MgAl}_{2} \mathrm{O}_{4}$ Spinel".C333

C334 Yanina, S.V. and Carter, C.B., 2000, Mat. Res. Soc. Symp. Proc., 586, 87-91 "On Dewetting of Reactive Silicate Glass Films on Single-Crystal Ceramic Substrates."

C336 Ravishankar, N. and Carter, C.B., 2000, Sintering Science and Technology, ed. by R. A. German, G. L. Messing, R. G. Cornwall, pp 264-270 "Interfaces, Glass and Liquid-Phase Sintering".

C339 Carter, C.B., Ravishankar, N and Yanina S.V., 2000, Grain Boundary Transactions: Ceram. Trans. 118 pp 411-417 "Glass in and on Ceramic Oxides."

Invited Talks Given on Aspects of this Research (1992-)

1. "An Overview of the Study of Interfaces Using TEM," February 1992, 3M Analytical Division, St. Paul, MN.

2. "Thin Ceramic Films: Growth and Reactions," March 1992, Texas Instruments, Dallas, TX.

3. "Growth of Thin Ceramic Films," April 1992, 3M Special Symposium on Inorganic Materials, St. Paul, MN.

4. "Interfaces and the Growth of Thin Oxide Films," 21 June 1992, International Conference on Intergranular and Interphase Boundaries, Thessaloniki, Greece.

5. "High-Resolution TEM of Ceramics," August 1992, EMSA Symposium on HighResolution TEM, Boston, MA.

6. "Interfaces in Ceramic Materials," 1 May 1993, NIST Ceramics Group Seminar, Gaithersburg, MD.

7. "Interfaces in Ceramic Materials," May 1993, Department of Materials Science, University of Wisconsin, Madison, WI.

8. "Interfaces in Ceramic Materials," June 1993, Argonne National Labs, Argonne, IL.

9. "High-Resolution TEM of Grain Boundaries," 26 September 1993, 2nd Interamerica Congress on Electron Microscopy, Cancun, Mexico.

10. "Thin Ceramic Films: Growth and Reactions," 1 November 1993, Departmental Colloquium, Department of Materials Science, University of Illinois, Urbana, IL.

11. "Interfaces in Ceramics," 13 July 1994, Max Planck Institut for Mikrostrukturphysik, Halle, Germany.

12. "The Role of Defects During Growth and Reactions in Oxides," 27 October 1994, Lausanne, Switzerland.

13. "Thin Ceramic Films: Growth and Reactions," 30 October 1994, Juilich, Germany.

14. "Growth and Reactions in Oxide Thin Films," 12 March 1995, University of California-Santa Barbara, Santa Barbara, CA.

15. "Reactions and Phase Transformations in Thin Oxide Films," 11 April 1995, Case Western Reserve University, Cleveland, $\mathrm{OH}$.

16. "Understanding Surfaces, Interfaces, \& Thin Films," 11 May 1996, Thirteenth Annual Spring Symposium of The New England Society for Electron Microscopy, Marine Biological Laboratories, Woods Hole, Massachusetts.

17. "AFM as a Complement to SEM and TEM in Materials Science," 23 May 1996, Microscopy Society of Northeastern Ohio Spring Symposium, Case Western Reserve University, Cleveland, $\mathrm{OH}$.

18. "Solid-State Reactions in Oxide Thin Films," 8 September 1996, Thirteenth International Symposium on the Reactivity of Solids, University of Hamburg, Hamburg, Germany. 
19. "Interaction between Glass and Surfaces: As Combined AFM, SEM, TEM Study," 13 October 1996, MICROMAT '96, Fifth Brazilian Conference on Microscopy of Materials, Rio de Janeiro, Brazil.

20. "AFM as a Complement to SEM and TEM in Materials Science," 27 October 1996, 15th NCSEM Annual Symposium on Advances in Microscopy, Wilmington, North Carolina.

21. "TEM of Ceramics," 4 April 1997, NCEM New Building/Microscope Dedication Symposium, Lawrence Berkeley National Lab., Berkeley, CA.

22. “Oxide Thin Films: Substrates, Growth and Reactions," 18 April 1997, MS\&E, North Carolina State University Department Seminar, Raleigh, NC.

23. “Oxide Thin Films: Substrates, Growth and Reactions," 28 April 1997, MS\&E, Arizona State University Department Seminar, Tempe, AZ.

24. "Electron and Scanning Probe Microscopy of Glass/Ceramic Interfaces," 4 August 1997, Ceramics Gordon Research Conference on New Perspectives in Interface Science, Kimball Union, NH.

25. "Reactions and Phase Transformations in Thin Oxide Films," 23 June 1997, Department of Materials, University of Leeds, UK.

26. "Microscopy of Ceramic Surfaces" 23-26 September 1997, 4th Interamerican Electron Microscopy Conference, Guayaquil, Ecuador.

27. "Surfaces in Oxides", 19 November 1997 CMS Seminar Los Alamos National Labs, NM.

28. "Faceting of Oxide Surfaces and Thin-Film Growth", 2 December 1997 Fall MRS.

29. "Microscopy of Ceramic Surfaces", February 1998, Spring Meeting of the Alabama Microscopy and Imaging Society.

30. "Dislocations in Ceramic Oxides" 12-16 July 1998, MSA Microscopy and Microanalysis Meeting, Symposium on Ceramics and Minerals, Atlanta, GA.

31. "A New Method to Study Solid-State Reactions in Oxides", 27 April 1998, Bayerisches Geoinstitut, Universitaet Bayreuth, Department Seminar.

32. "Oxide Thin Films and Surfaces" 18 May 1998, University of Karlsruhe, Laboratorium für Elektronenmikroskopie, Department Seminar.

33. "Oxide Thin Films and Reactions", 5 June 1998, University of Erlangen, Department Seminar.

34. "A New Method to Study Solid-State Reactions", 1 July 1998, University of Köln, Department Seminar.

35. "Reactions in and on Oxides", 7 July 1998, University of Hannover, Department Seminar.

36. "The Future of Transmission Electron Microscopy", 25 September 1998, Carnegie Mellon University.

37. "Glass Films in and on Oxides", 5 October 1998, PPG, Pittsburgh, PA.

38. "The Future of Transmission Electron Microscopy", 15 October 1998, Minnesota Microscopy Society Fall Meeting.

39. "Glass Films in and on Oxides", 22 October 1998, Fall Meeting, American Ceramic Society.

40. "Interfaces in Ceramics", 26 October 1998, Acta Materialia Topical Conference, La Jolla, $\mathbf{C A}$.

41. "Glass Films in and on Oxides", 14 December 1998, Lawrence Berkeley National Lab.

42. "Reactions in and on Oxide Thin Films", 19 March, 1999, Cambridge University, UK.

43. "Ceramic Surfaces", 27 April, 1999, Spring Meeting, American Ceramic Society.

44. "Faceting of Oxide Surfaces and Thin-Film Growth", 12 April, 1999, Clemson University.

45. "Reactions in and on Oxide Thin Films", 11 May 1999, University of Wisconsin. 
46. "Archie Howie Symposium: Celebrations in Pioneering Electron Microscopy", 3 August 1999, Microscopy \& Microanalysis '99, and "Interfaces Symposium", Portland Oregon.

47. “Ceramic Surfaces, Interfaces and Wetting", 28 September 1999, Department of Energy.

48. "Ceramic Surfaces, Interfaces and Wetting", 15 October 1999, University of Michigan, Ann Arbor, MI.

49. "SEM of Ceramic Surfaces", 26 October 1999, CIASEM, IntraAmerica Society for Electron Microscopy, Caracas, Venezuela.

50. "Some Fundamental Aspects of Liquid-phase Sintering", 28 October 1999, Presented by Dr. Ravishankar, Fall Meeting, American Ceramic Society, Seattle, WA.

51. "Ceramic Surfaces, Interfaces and Wetting", 16 November 1999, Georgia Tech., Atlanta GA.

52. "Ceramic Surfaces, Grain Boundaries and Crystalline Interphases", 10 February 2000, AIMS Annual Spring Meeting, Tucson, AZ.

53. "Glass in and on Ceramic Oxides", 15-17 March 2000, Japan FCC Int Workshop, Nagoya, Japan.

54. . "Glass in and on Ceramic Oxides", 6 April 2000, Virginia Tech., Blacksburg, VA.

55. "Mechanism of Glass-Crystal Boundary Migration in Ceramics" with $N$. Ravishankar, 2 May 2000, Annual meeting, American Ceramic Society, St Louis MI, 2000 (BS5-002-00)

56. "Discussion of the Choice of Length Scales in Grain Boundary Studies" Lead opinion at Solid State Studies in Ceramics: Gordon Research Conference, 9 August 2000

57. "Glass in and on Ceramic Oxides", Portland State University. MSE Department Seminar, 1 November, 2000

58. "Glass in and on Ceramic Oxides", Cal. Tech. MSE Department Seminar, 21 February, 2001

59. "Interfaces in Ceramics", IFW Dresden July, 2002

60. "Surfaces and Grain Boundaries in Ceramics", At CIASEM-VI October 2001.

61. "Diffraction Contrast in the TEM: A Series of Lectures." Department of Materials Science, Cath. Univ., Rio de Janiero, Oct. 2002.

62. "Ceramic Interfaces" Annual Meeting Brazilian Society of EM, Sao Paulo, Oct. 2001.

63. "Model Studies of Glass in Alumina Grain Boundaries" Int. Symp. On Science \& Technology of Alumina, Ringberg, Germany, March 17. 2002.

64. "Characterization of Composite Materials by Combined EM Techniques" Microscopy of Composites, Oxford, 26 March 2002

65. "Interface structure and characterization and/or (de)wetting behavior" Surfaces and Interfaces Symposium at the 105th Annual American Ceramic Society Meeting April 27-30, 2003 in Nashville, TN

\$5 Personnel who worked on this Award (92-00)

The graduate students who worked on this program and were fully supported by DOE were/are

Mike Mallamaci (Ph.D. 94)

now Goodyear in Akron, $\mathrm{OH}$ 
Sundar Ramamurthy (Ph.D. 96)

Mr. Andrey Zagrebelny (Ph.D. 00)

Ms Svetlana Yanina (Ph.D. 01)

Jeff Farrer (expected 2001)

The undergraduates who worked on this program and were fully supported by DOE were/are

Kevin Sartain

Cathy Zimmerman

Brian Hebert

Ryan Thompson

Shelley Krebsbach

Greg Johnson

Rachael Strickland

Kris Goman

The postdocs who worked on this program and were partially supported by DOE were/are

Zhigang Mao

N. Ravishankar now Applied Materials, Santa Clara, CA

now Cypress Semiconductor in Bloomington MN

now postdoc at MIT.

now TSL; Thesis still in progress

now with Kimberley Clark

$\mathrm{U}$ of Texas Grad. School

now at Sony Corp

formerly at Sony Corp; now UMN Grad. School

now UMN Grad. School (Ms. Gilliss)

now at Seagate

former Chem. E. undergrad.

former Mat. Sci. undergrad.

$\$ 6$ References used in this proposal

1. Clarke, D.R., Intergranular Phases in Polycrystalline Ceramics, in Surfaces and Interfaces of Ceramic Materials, L.-C. Dufour, C. Monty, and G. Petot-Ervas, Editors. 1989, Kluwer Academic Publishers: Dordrecht. p. 57-79.

2. Norton, M.G. and Carter, C.B., Grain and Interphase Boundaries in Ceramics and Ceramic Composites, in Atomic-Level Properties of Interface Materials, D.W.a.S. Yip, Editor. 1992, Chapman and Hall: London. p. 151-189.

3. Kingery, W.D., Densification during Sintering in the Presence of a Liquid Phase 1. Theory. J. Appl. Phys., 1959. 30 301-306.

4. Huppmann, W.J., Riegger, H., Kaysser, W.A., Smolej, V., and Pejovnik, S., The Elementary Mechanisms of Liquid Phase Sintering. I. Rearrangement. Z. Metallk, 1979. 70 707-713.

5. German, R.M., Sintering Theory and Practice. 1996, New York: John Wiley and Sons, Inc. 550.

6. Clarke, D.R., Grain Boundaries in Polycrystalline Ceramics. Ann. Rev. Mater. Sci., 1987. 17 . 57-74.

7. Cinibulk, M.K., Kleebe, H.-J., Schneider, G.A., and Rühle, M., Amorphous Intergranular Films in Silicon Nitride Ceramics Quenched from High Temperatures. J. Am. Ceram. Soc., 1993. 76(11) 2801-808.

8. Clarke, D.R., Shaw, T.M., Philipse, A.P., and Horn, R.G., Possible Electrical Double-Layer Contribution to the Equilibrium Thickness of Intergranular Glass Films in Polycrystalline Ceramics. J. Am. Ceram. Soc., 1993. 76(5) 1201-1204.

9. Kingery, W.D., Bowen, H.K., and Uhlmann, D.R., Introduction to Ceramics. 2nd ed. Wiley series on the science and technology of materials, ed. E. Burke, B. Chalmers, and J.A. Krumhansl. 1976, New York: Wiley-Interscience.

10. Padture, N.P. and Chan, H.M., Improved Flaw Tolerance in Alumina Containing 1. vol.\% Anorthite via Crystallization of the Intergranular Glass. J. Am. Ceram. Soc., 1992. 75(7) 1870-75. 
11. Padture, N.P. and Chan, H.M., On the Constrained Crystallization of Synthetic Anorthite (CaO.Al $\mathrm{O}_{3} . \mathrm{SiO}_{2}$ ). J. Mater. Res., 1992. 7(1) 170-177.

12. Ravishankar, N. and Carter, C.B. Migration of Silicate Liquids out of Grain Boundaries in Ceramics. in Microsc. Microanal., 1999. 5(2) 800-801

13. Ramamurthy, S., Mallamaci, M.P., Zimmerman, C.M., Carter, C.B.; Duncombe, P.R., and Shaw, T.M., Microstructure of Polycrystalline $M g O$ Penetrated by $a$ Silicate Liquid. Microsc. Microanal., 1996. 2(3) 113-128.

14. Flaitz, P.L. and Pask, J.A., Penetration of Polycrystalline Alumina by Glass at High temperatures. J. Am. Ceram. Soc., 1987. 70(7) 449-55.

15. Simpson, Y.K. and Carter, C.B., Faceting Behavior of Alumina in the Presence of a Glass. J. Am. Ceram. Soc., 1990. 73(8) 2391-2398.

16. Susnitzky, D.W. and Carter, C.B., Structure of Alumina Grain Boundaries Prepared with and without a Thin Amorphous Intergranular Film. J. Am. Ceram. Soc., 1990. 73(8) 2485-93.

17. Shaw, T.M. and Duncombe, P.R., Forces between Aluminum Oxide Grains in a Silicate Melt and Their Effect on Grain Boundary Wetting. J. Am. Ceram. Soc., 1991. 74(10) 2495-505.

18. Ueno, F. and Horiguchi, A. Grain Boundary Phase Elimination and Microstructure of Aluminium Nitride. in Euro-Ceramics. 1992: Elsevier Applied Science.

19. Drennan, J., Clarke, D.R., Hannink, R.H.J., and Shaw, T.M., Effect of Oxygen Partial Pressure during Sintering on the Microstructure of Mg-PSZ with Strontia and Silica Additions. J. Am. Ceram. Soc., 1994. 77(8) 2001-2008.

20. Mallamaci, M.P. and Carter, C.B., Crystallization of pseudo-orthorhombic anorthite on basal sapphire. J. Am. Ceram. Soc., 1999. 82(1) 33-42.

21. Ramamurthy, S., Hebert, B.C., Carter, C.B.; and Schmalzried, H., Interaction of Silicate Liquid with Sapphire Surfaces. Mat. Res. Soc. Symp. Proc., 1996. 398 295-300.

22. Ramamurthy, S., Amorphous-Crystalline Interfaces in Oxide-Ceramics, in Chem. Emng. \& Mats. Sci. 1996, U. of Minnesota: Minneapolis.

23. Heffelfinger, J.R. and Carter, C.B., Mechanisms of surface faceting and Coarsening. Surf. Sci., 1997. 39 188-200.

24. Heffelfinger, J.R., Bench, M.W., and Carter, C.B., On the faceting of Ceramic Surfaces. Surf. Sci. Lett., 1995. 343 1161-66.

25. Dorre, E. and Hubner, H., Alumina-Processing, Properties, and Applications. 1984, Berlin: Springer-Verlag.

26. Powell-Dogan, C.A., Grain-Boundary Crystallization in 96\% Alumina Ceramics. 1989, Case Western Reserve University.

27. Wiederhorn, S.M., Ultra-Fine Grain Ceramics. 1970, New York: Syracuse University Press.

28. Mencik, J., Strength and Fracture of Glass and Ceramics. 1992, Amsterdam: Elsevier.

29. Wulff, G., Zur Frage der Geschwindigkeit des Wachstums und der Auflosung der Krystallflachen. Z. Krist., 1901. 34 449-530.

30. Mullins, W.W., Theory of Linear facet Growth During Thermal Etching. Phil. Mag., 1961. 6 1313-1341.

31. Heffelfinger, J.R., Bench, M.W., and Carter, C.B., Steps and the Structure of the (0001) $\alpha$-Alumina Surface. Surface Science, 1997.370 L168-L172.

32. Tasker, P.W., The Stability of Ionic Crystal Surfaces. J. Phys. C, 1979. 124977.

33. Yanina, S.V. and Carter, C.B., Terraces and Ledges on (001) Spinel Surfaces. Surf. Sci., 2002. 513 LA02-LA12.

34. Yanina, S.V. and Carter, C.B., Dislocations at Spinel Surfaces. Surf. Sci., 2002. 511 133-146.

35. Lange, F.F. and Clarke, D.R., Morphological Changes of an Intergranular Thin Film in a Polycrystalline Spinel. J. Am. Ceram. Soc., 1982. 65(10) 502-506. 
36. Raj, R. and Lange, F.F., Crystallization of small quantities of glass (or a liquid) segregated in grain boundaries. Acta Metall., 1981. 29 1993-2000.

\section{$\$ 7$ Collaborations}

The topic under investigation is a very important one in the field of ceramics. No group can be fully qualified and equipped to carry out a comprehensive study even when the number of materials is limited. It is our experience that students benefit enormously from interactions with researchers having other fields of expertise; it is intended to continue this approach in the proposed program.

\section{Ongoing collaborations}

Hermann Schmalzried (Hanover Germany). We have collaborated with Prof. Schmalzried since 1979. His influence on our research programs has been profound. He is continuing this collaboration as an Emeritus status, having spent 7 weeks with us in 1999. Prof. Schmalzried's expertise is the thermodynamics and kinetics of reactions in oxide systems; he is the author of two classic texts on this subject.

Manfred Rühle (Stuttgart, MPI, Germany). CBC spent 3 months of his sabbatical leave in Stuttgart. Stuttgart has the ARM (a $1 \AA$-resolution TEM). No funds are requested for this work in this program. HRTEM will only be used if it becomes particularly relevant for understanding new structures.

Joe Michael (Sandia, Albuquerque) has agreed to continue our collaboration using EBSD to study thin films and reactions in oxides. We have worked with Dr. Joe Michael at Sandia during the past three years using EBSD but published our first joint paper in 1989. Jim Bentley and Ian Anderson (ORNL) have both agreed to continue our long-standing collaboration on the analytical EM of oxides. First joint paper with Dr. Bentley was 1986.

Former collaborators \& group members

The following list includes researchers with whom the P.I. has collaborated during the past 5 years. Collaboration here is defined as joint work which involved funding or led to a published paper or conference abstract. Collaborators at the $\mathrm{U}$ of $\mathrm{MN}$ or former group members are not listed as collaborators.

\section{Current group members:}

Blanford, Chris

Gilliss, Shelley

Farrer, Jeff

Li, Min

Schwittala, Suzanne

Yanina, Svetlana

McKernan, Janet

Ravishankar, N. (Ravi)

Goman, Kristine
Co-advised Ph.D. student. Started his $5^{\text {th }}$ year in Sept. 1999.

Ph.D. student. Started her $1^{\text {t }}$ year in Sept. 1999. $4^{\text {th }}$ year in our group.

Ph.D. student. Started his $4^{\text {th }}$ year in Sept. 1999

Co-advised Ph.D. student. Started her $3^{\text {rd }}$ year in Sept. 1999.

Ph.D. student. Full-time student since Sept. 1998

Ph.D. student. Started her $5^{\text {th }}$ year in Sept. 1999

Junior Scientist (part-time)

Postdoc. Started his $2^{\text {ad }}$ year June 1999

Undergrad. Junior Yr 
Strickland, Rachael $\quad$ Undergrad. Junior/Senior Yr

Collaborators (in last 5 years):

\begin{tabular}{ll} 
Angelo, Jim & Seagate, Bloomington, MN \\
Bartelt, Norm & Sandia National Labs, Livermore, CA \\
Bentley, Jim & Oak Ridge National Labs, Oak Ridge, TN \\
Bob Hwang & Sandia National Labs, Livermore, CA \\
Bristowe, Paul & University of Cambridge, UK \\
Campbell, Geoff & Livermore National Labs, Livermore, CA \\
Dickerson, Rob & Los Alamos National Labs, Los Alamos, NM \\
Gemming, Thomas & Max-Planck Institute, Stuttgart, Germany \\
Hamilton, John & Sandia National Labs, Livermore, CA \\
King, Wayne & Livermore National Labs, Livermore, CA \\
Medlin, Doug & Sandia National Labs, Livermore, CA \\
Michael, Joe & Sandia National Labs, Albuquerque, NM \\
Mills, Mike & Ohio State University, Columbus, OH \\
Mitchell, Terry & Los Alamos National Labs, Los Alamos, NM \\
Ruhle, Manfred & Max-Planck Institute, Stuttgart, Germany \\
Schmalzried, Hermann & University of Hanover, Germany \\
\hline
\end{tabular}

\section{$\$ 8$ Illustrations}

The following illustrations have been chosen to highlight some of the achievements of the previous program

1. Making bicrystals of alumina containing layers of glass

2. Crystallizing glass

3. Penetration of glass through a dense polycrystalline $\mathrm{MgO}$

4. Glass droplets on alumina surfaces

5. Evaporation from surfaces in the presence of silicate liquid

6. Mechanical properties of glass films

7. Reconstruction of the surface of basal alumina

8. The 001 surface of spinel

9. Exuding glass from grain boundaries in alumina

The next three illustrations are from our preliminary studies of the work proposed in the current proposal

10. Migration of glass-containing grain boundaries in alumina

11. TEM of a migrating grain boundary in alumina using a specimen prepared by FIB

12. Moving triple junction in alumina

13. EBSD of migrating grain boundaries in alumina 


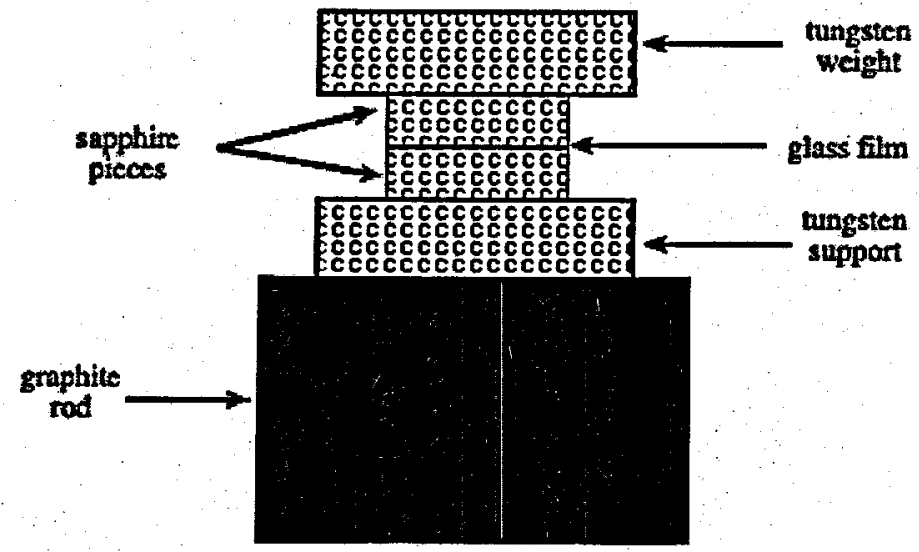

Figure 1a. The experimental geometry used for fabricating thin glass-layer bicrystals. The bicrystal is hot pressed in a vacuum furnace at approximately $1980^{\circ} \mathrm{C}$. The thin-film coating consists of anorthite $\left(\mathrm{CaAl}_{2} \mathrm{Si}_{2} \mathrm{O}_{8}\right)$ glass deposited by PLD. A tungsten block. provides a pressure of $12 \mathrm{kPa}$ at the interface.

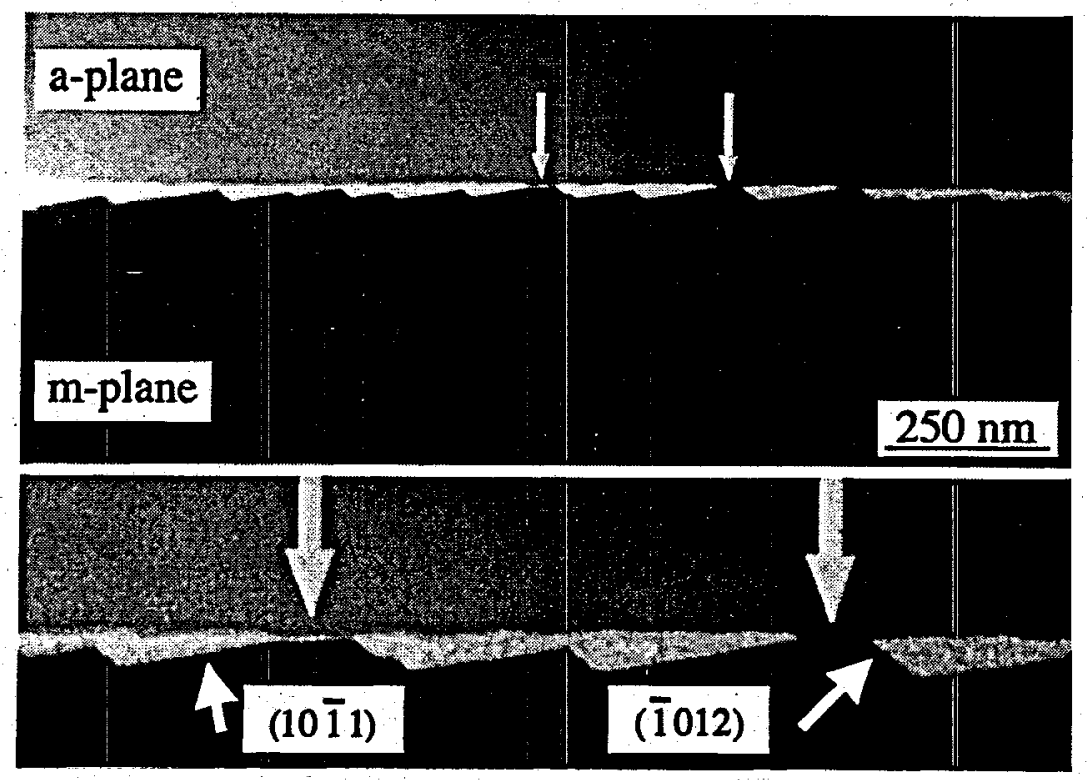

Figure 1b. $A$ diffuse-scattering dark-field image of a region of $\mathrm{Al}_{2} \mathrm{O}_{3}$ bicrystal. The initial surface of the lower crystal is $(10 \overline{1} 0)$ while that for the upper crystal is $(11 \overline{2} 0)$. The figure shows the layer of glass to be very thin $(<100 \mathrm{~nm})$ with both the $(10 \mathrm{1} 0)$ and (1120) $\mathrm{Al}_{2} \mathrm{O}_{3}$ /glass interfaces exhibiting faceting. In this region it appears that the glass layer is no longer continuous, and flat facets with (1010) planes in contact with the (1120) planes are observed. These flat contacts are separated by triangular pockets of glass bounded by $(10 \overline{1} 1)$ and (1012) facets in the lower crystal, and the (1150) surface in the upper crystal. The upper $\left(11 \overline{2}^{20} \mathrm{Al}_{2} \mathrm{O}_{3}\right.$ /glass interface is also faceted, but appears wavy since it is.not being viewed edge-on. For more details see paper J204 in Appendix. 


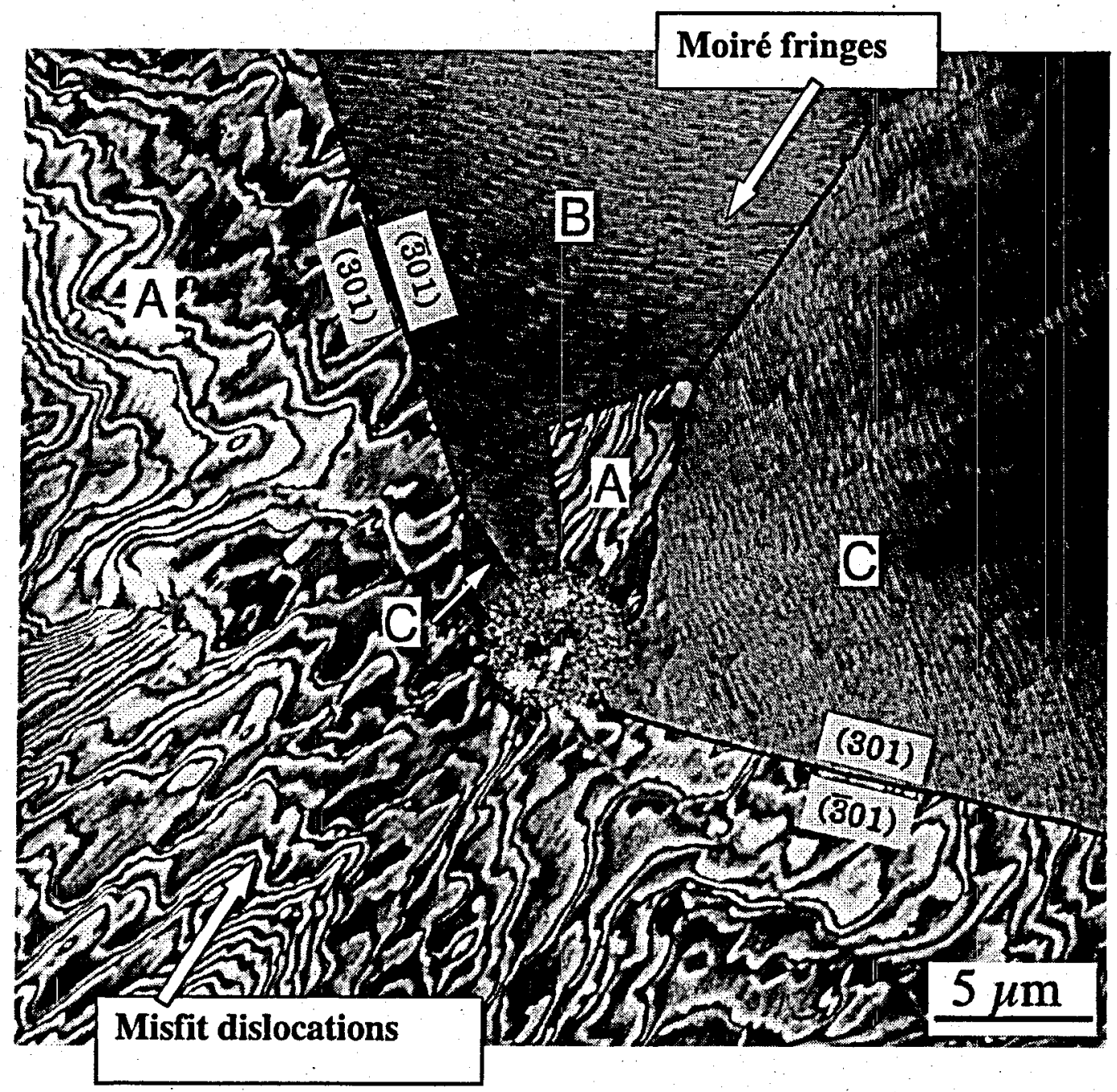

Figure 2. Two-beam dark-field TEM image of crystallized multivariant pseudoorthorhombic anorthite $\left(\mathrm{CaAl}_{2} \mathrm{Si}_{2} \mathrm{O}_{8}\right)$ on $(0001) \mathrm{Al}_{2} \mathrm{O}_{3}$. The image was taken using a (3300) reflection from the $\mathrm{Al}_{2} \mathrm{O}_{3}$ substrate, which corresponds to $(600)$ in variant $\mathrm{A}$ and $\{303\}$ in variants $B$ and $C$. Two tri-junctions between all three variants can be seen in the image. Variant $A$ shows irregular contrast associated with the interfacial dislocation network while variants $\mathrm{B}$ and $\mathrm{C}$ display rotational moire fringes. The wavy contrast seen in the type-A variant is typical of images formed using two-beam conditions with the $(\overline{3} 300)_{\mathrm{Al}_{2} \mathrm{O}_{3}} /(600)_{\text {o-non }}$ reflections excited. For more details see paper $\mathrm{J} 208$ in Appendix. 

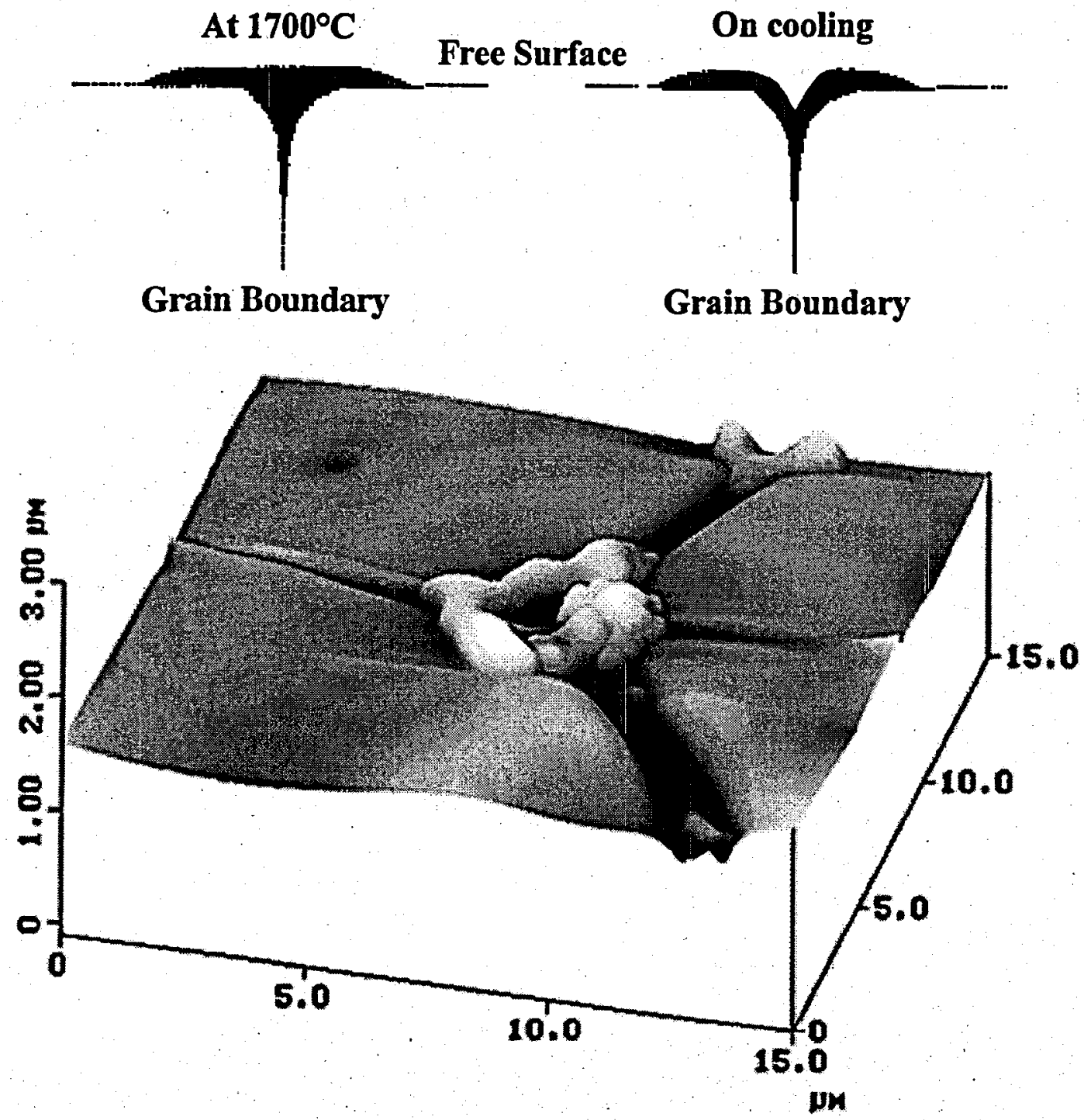

Figure 3. AFM image showing a triple-grain junction in $\mathrm{MgO}$. The junction is decorated by a crystallite of monticellite. The schematic at the top illustrates the liquid silicate (monticellite) retracting from the surface into the triple junction. The liquid crystallizes on cooling the sample and gives the morphology observed in the AFM. For more details see paper J182 in Appendix. 


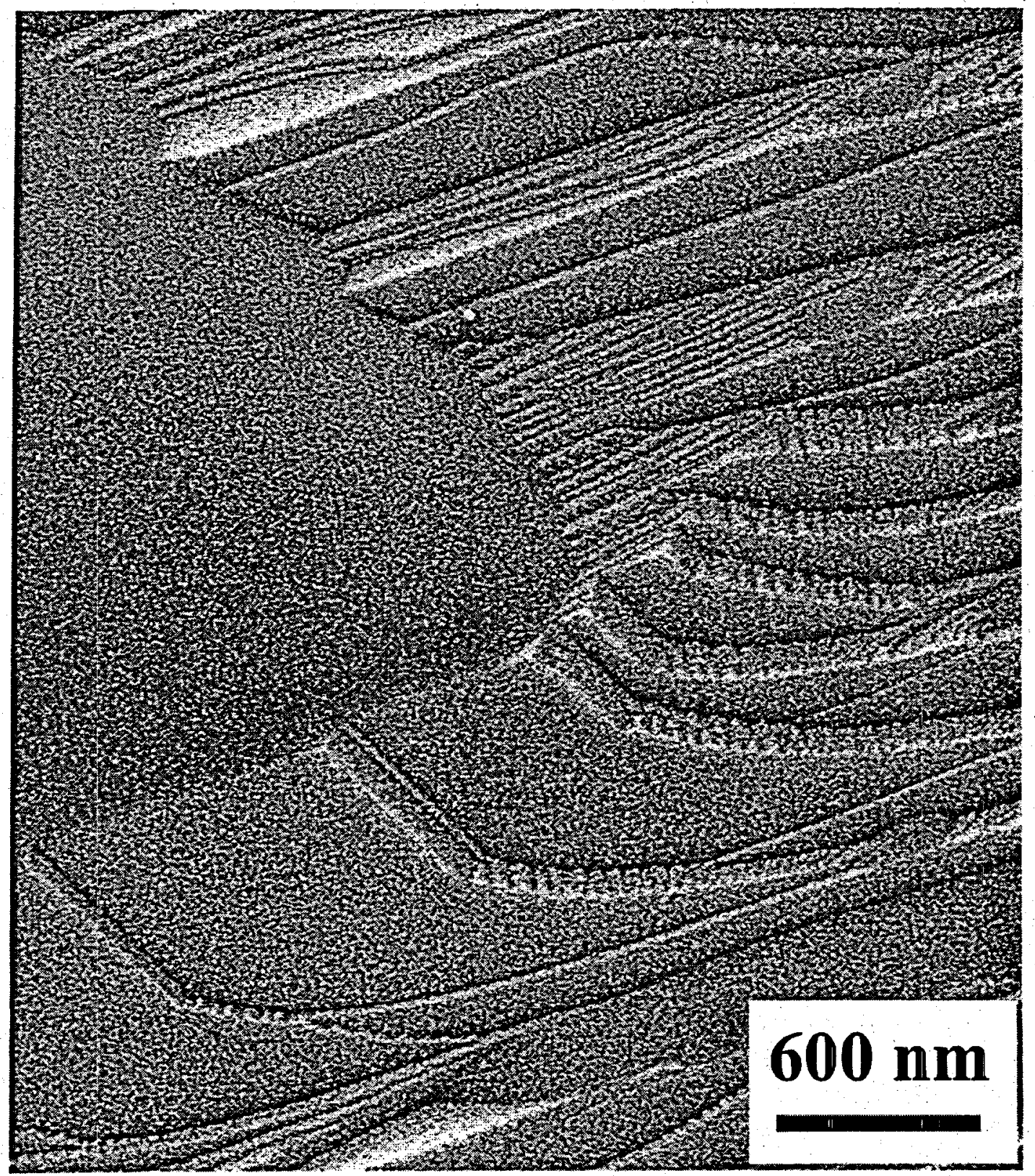

Figure 4a. SE image of dewet anorthite droplets on the m-plane of $\mathrm{Al}_{2} \mathrm{O}_{3}$ showing the details of the SLV triple junction. The m-plane reconstructs into (1011) and (I012) facets during the hightemperature anneal. The faceting of the m-plane significantly affects the morphology of the dewet droplets. The facets bend in the vicinity of the triple junction. Microfaceting of the steps is seen in the image. 


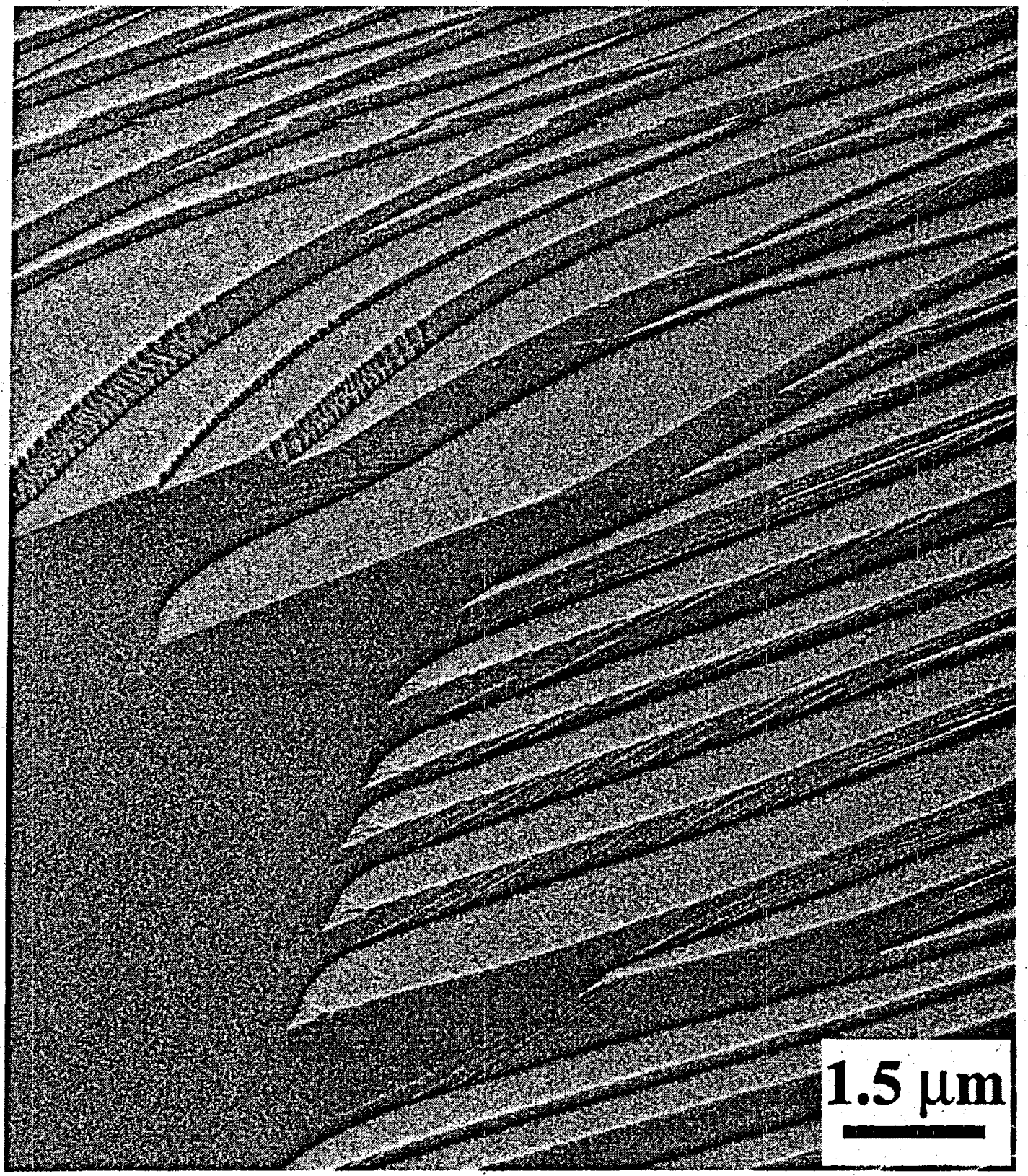

Figure $4 \mathrm{~b}$. SE image from a sample cooled slowly in the furnace. The anorthite glass spreads preferentially along one type of facet. The glass phase appears dark in the image. Analysis of the facets indicates that the liquid spreads along the $\{1012\}$ facet on the $\mathrm{m}$ plane of $\mathrm{Al}_{2} \mathrm{O}_{3}$. Microfaceting of this facet can also been seen in the image. 


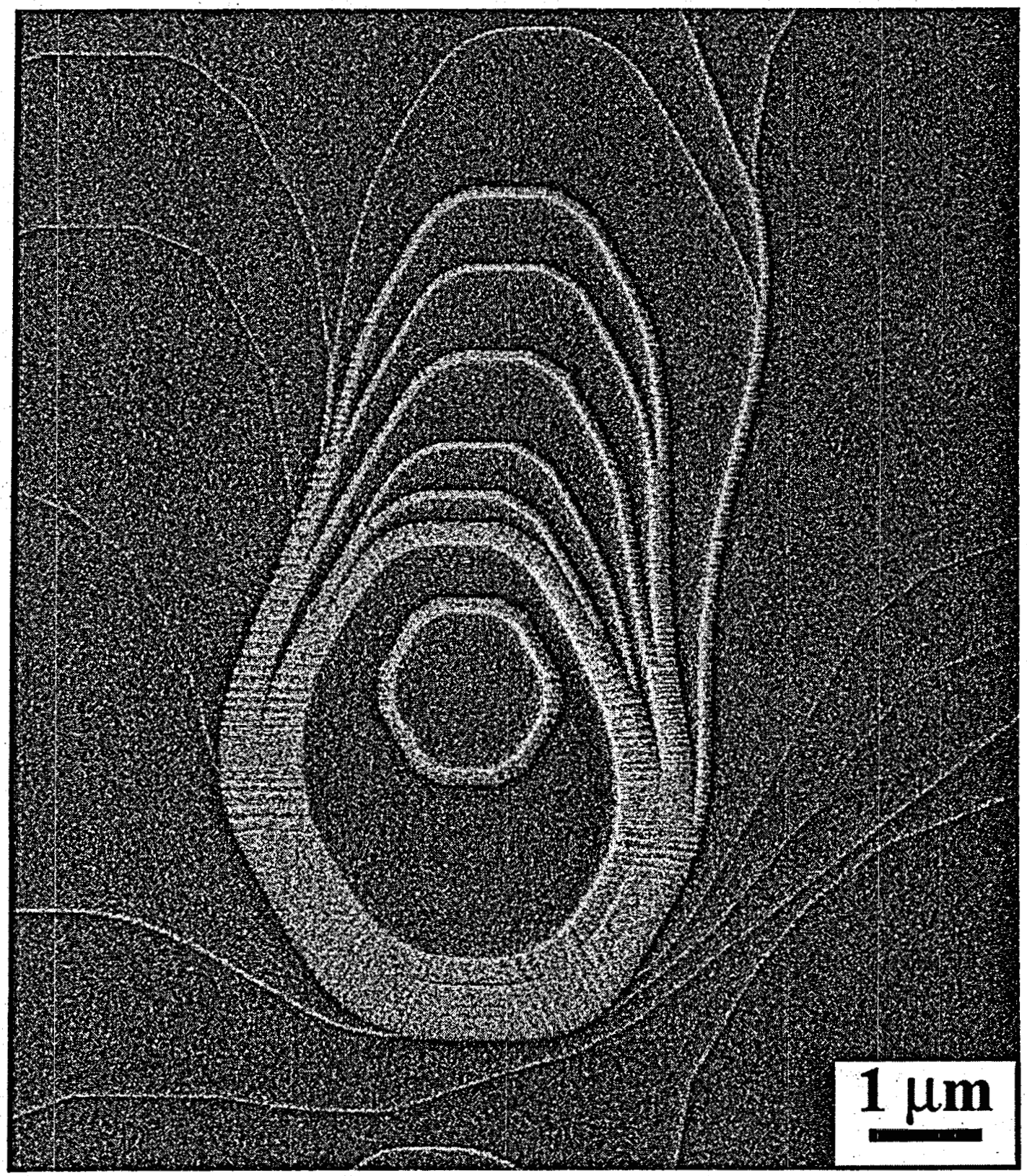

Figure 5. SE image showing the morphology after evaporation from a region that contained a silicate phase (celsian) on the (0001) plane of $\mathrm{Al}_{2} \mathrm{O}_{3}$ surface. Evaporation is slowest from the region beneath the droplet. The steps on the surface curve around the droplet and form a series of plateaus. 

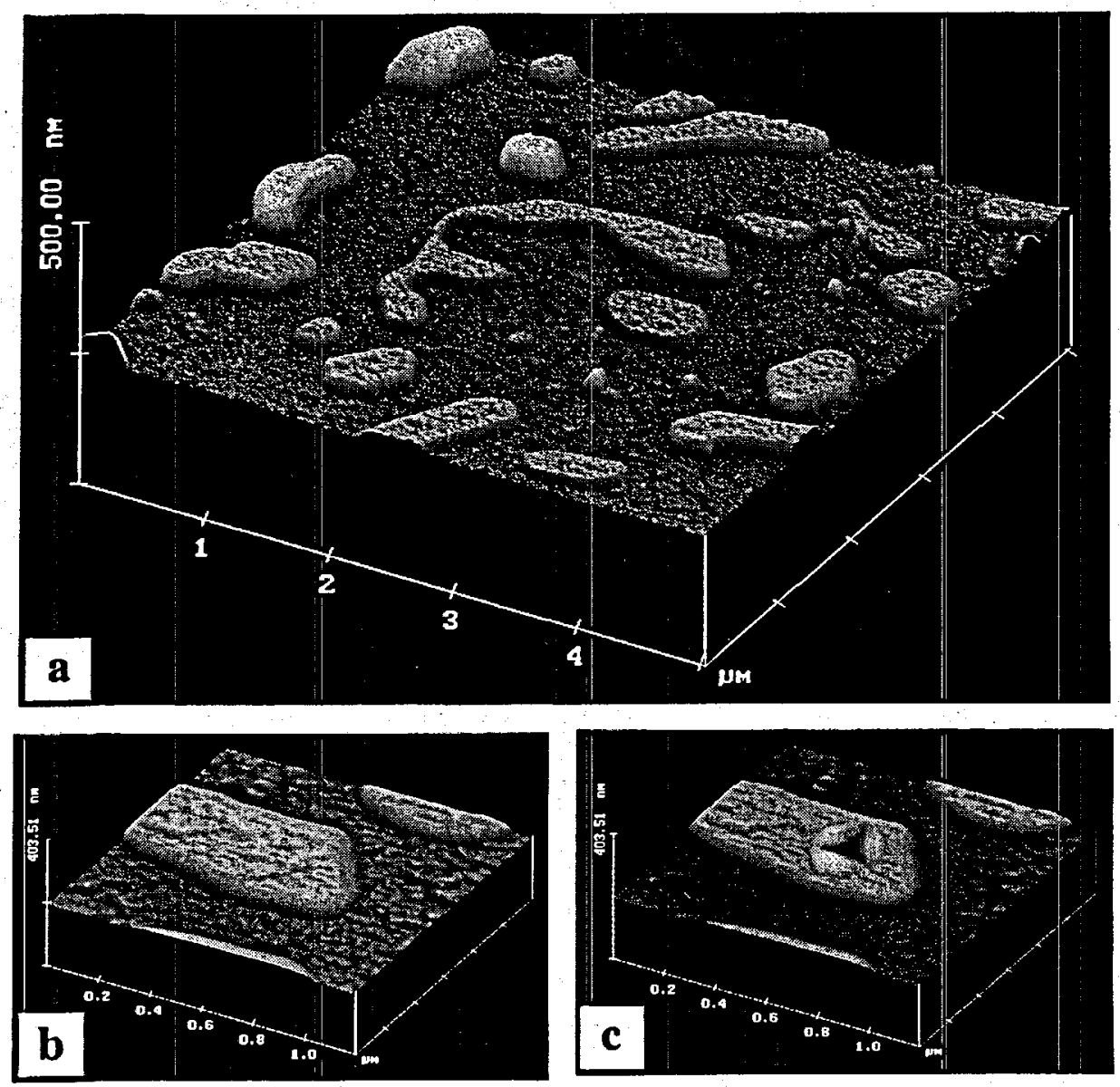

Surface-plot SPM/indenter images and load-displacement curves.

Figure 6a. Large-scale image of a dewetted crystallized anorthite film on a (0001) $\mathrm{Al}_{2} \mathrm{O}_{3}$ surface.

Figure $6 \mathrm{~b}$. The image of the region of the silicate film selected for indentation.

Figure $6 c$. The image of the same region of the silicate film taken immediately after the indentation. 


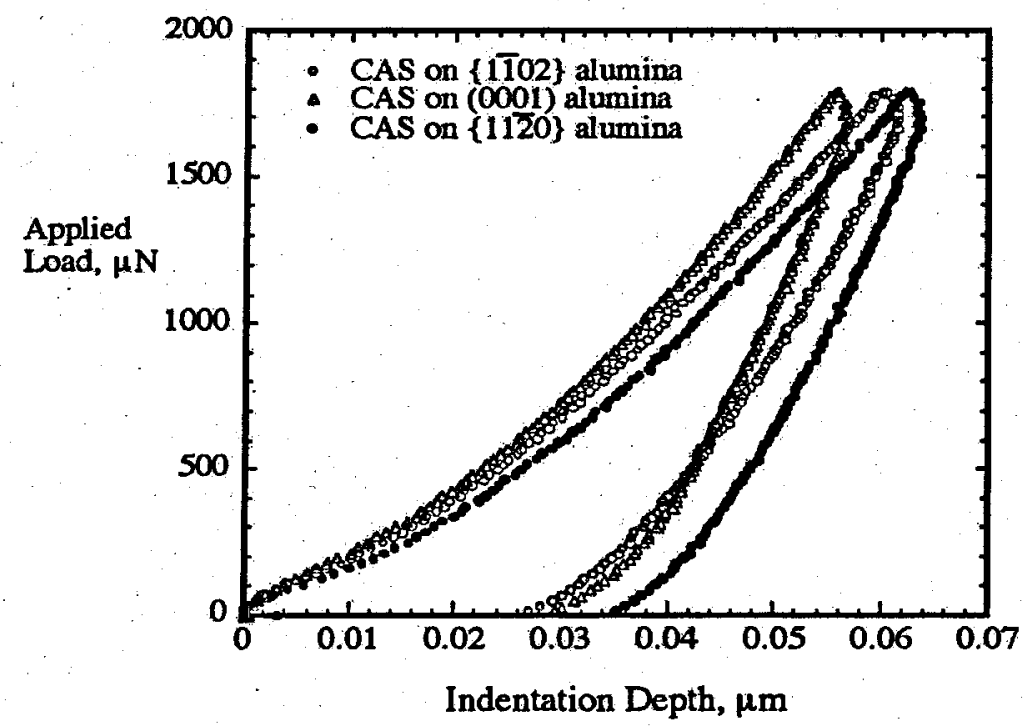

Figure 6d. The comparison of the load-displacement data for $\mathrm{CaAl}_{2} \mathrm{Si}_{2} \mathrm{O}_{8}$ (CAS) films grown on $\mathrm{Al}_{2} \mathrm{O}_{3}$ substrates of three different orientations. The indentation loads were up to $1.8 \mathrm{mN}$. Note the dependence of the curve position on the substrate crystallography.

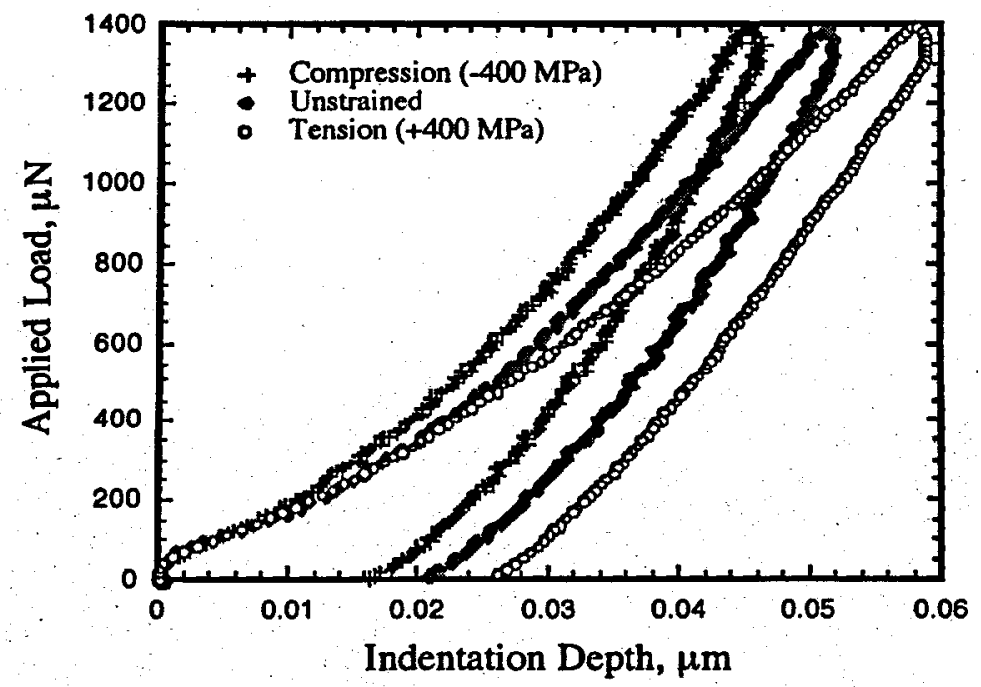

Figure 6e. The comparison of the load-displacement data for CAS films grown on the (0001) $\mathrm{Al}_{2} \mathrm{O}_{3}$ substrate. The residual stresses in the films were produced by straining the substrates during the growth to $\pm 0.4 \mathrm{GPa}$. The indentation loads were up to $1.8 \mathrm{mN}$. Note the dependence of the curve position on the amount and nature of the stress in the film. For details see paper J213 in Appendix. 
Figure 7. Line-plot SPM images of a $\{1010\} \mathrm{Al}_{2} \mathrm{O}_{3}$ surface that has been annealed at $1400^{\circ} \mathrm{C}$ for 8 hours:

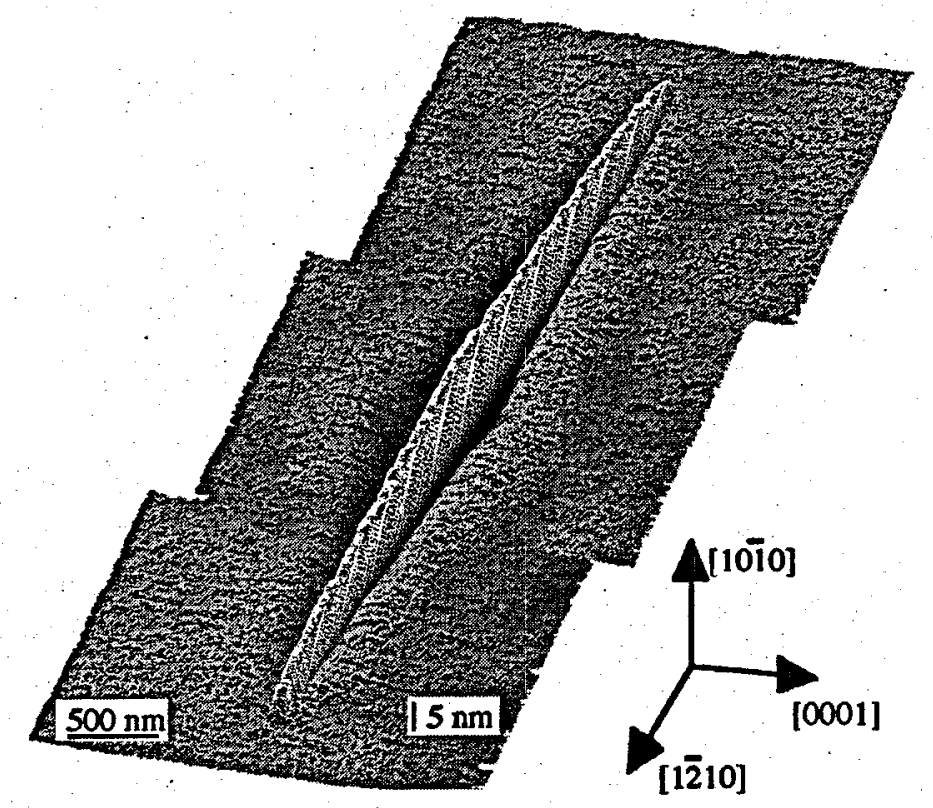

Figure 7a. Image of a single facet developed along the $[1 \overline{2} 10]$ direction in the crystal.

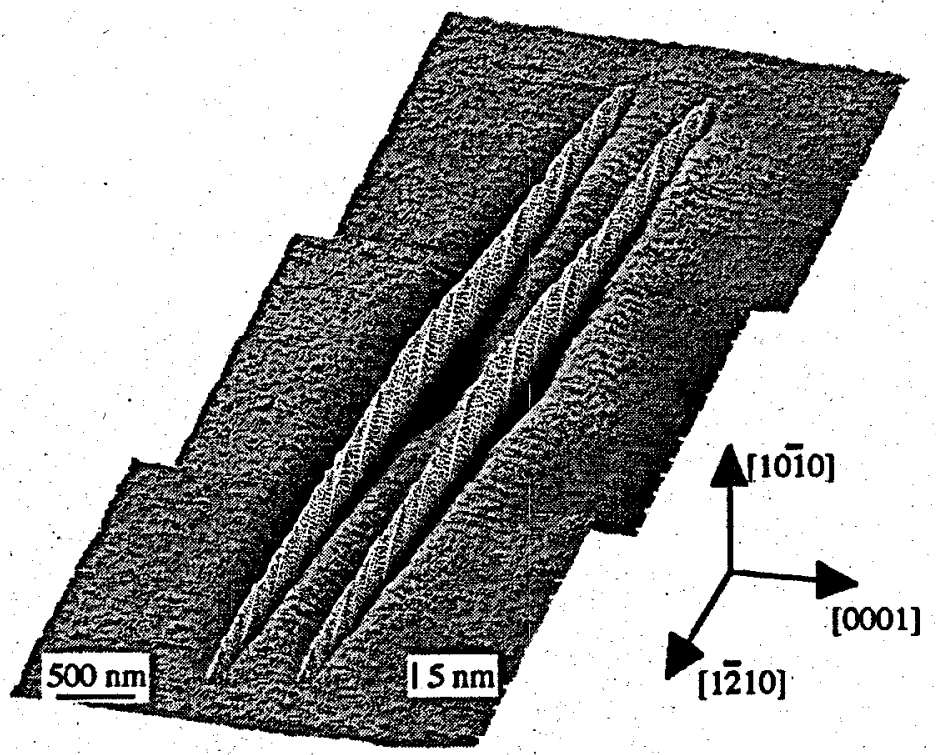

Figure 7b. Image of a pair of collinear facets developed along the $[1 \overline{2} 10]$ direction in the crystal. The growth of the original facet is expected to influence the nucleation site position and the direction of growth of the second facet. For details, see paper J194 in the Appendix. 
Figure 8. The dynamics of step motion on evaporating $\{001\}$ surface of $\mathrm{MgAl}_{2} \mathrm{O}_{4}$. Straight surface steps are aligned along the $\langle 110\rangle$ and the $<1 \overline{10}>$ directions of the crystal.
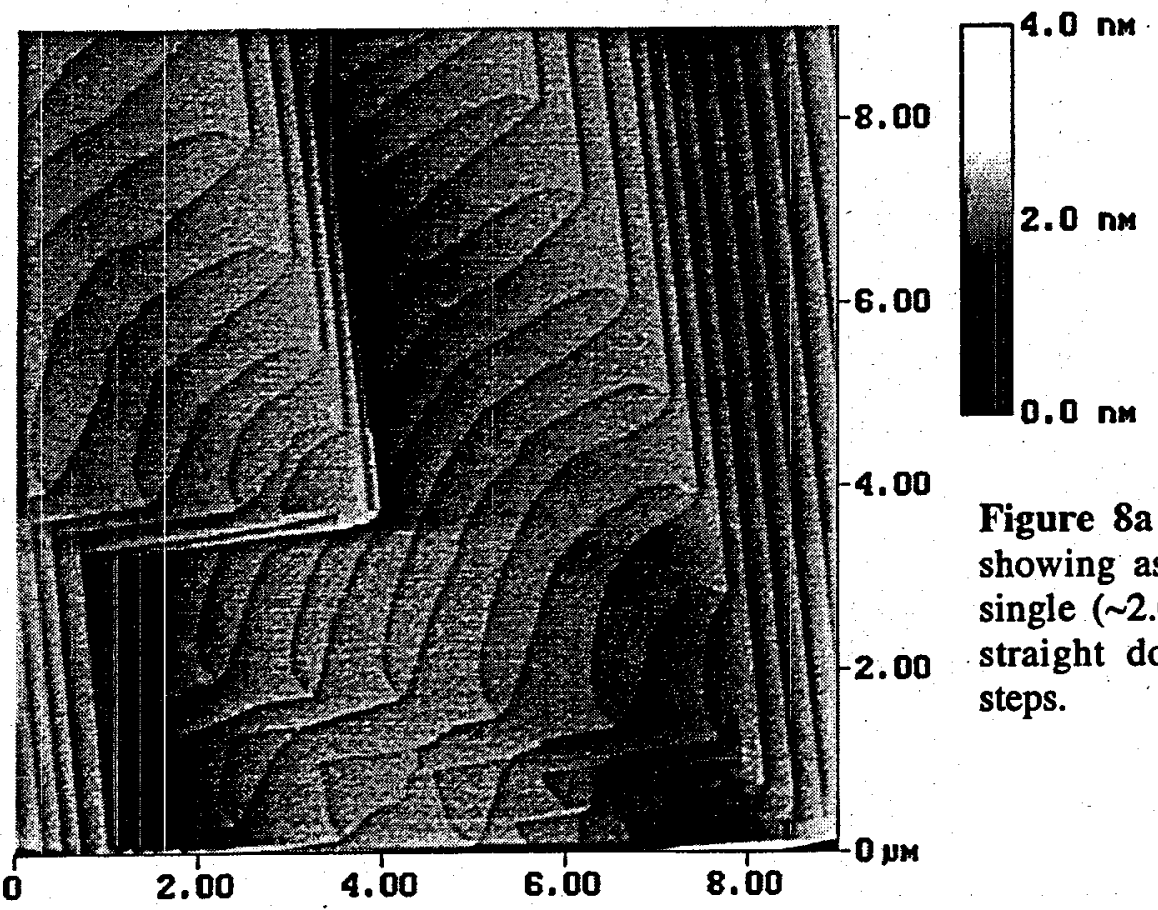

Figure 8a Height SPM image showing association of curved single ( 2.0- $\AA$-high) steps into straight double $(\sim 4.0-\AA$-high) steps.

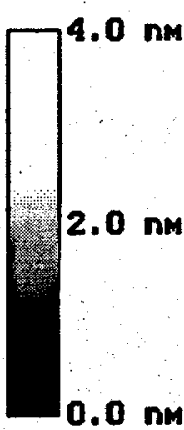

Figure 8b. Height SPM image of evaporation spiral produced by a dislocation terminating on the \{001\} surface of $\mathrm{MgAl}_{2} \mathrm{O}_{4}$. Straight double steps which are $\sim 4.0 \AA$ high form spiral sides and dissociate into pairs of straight single $(\sim 2.0-\AA$ high) steps in spiral corners.

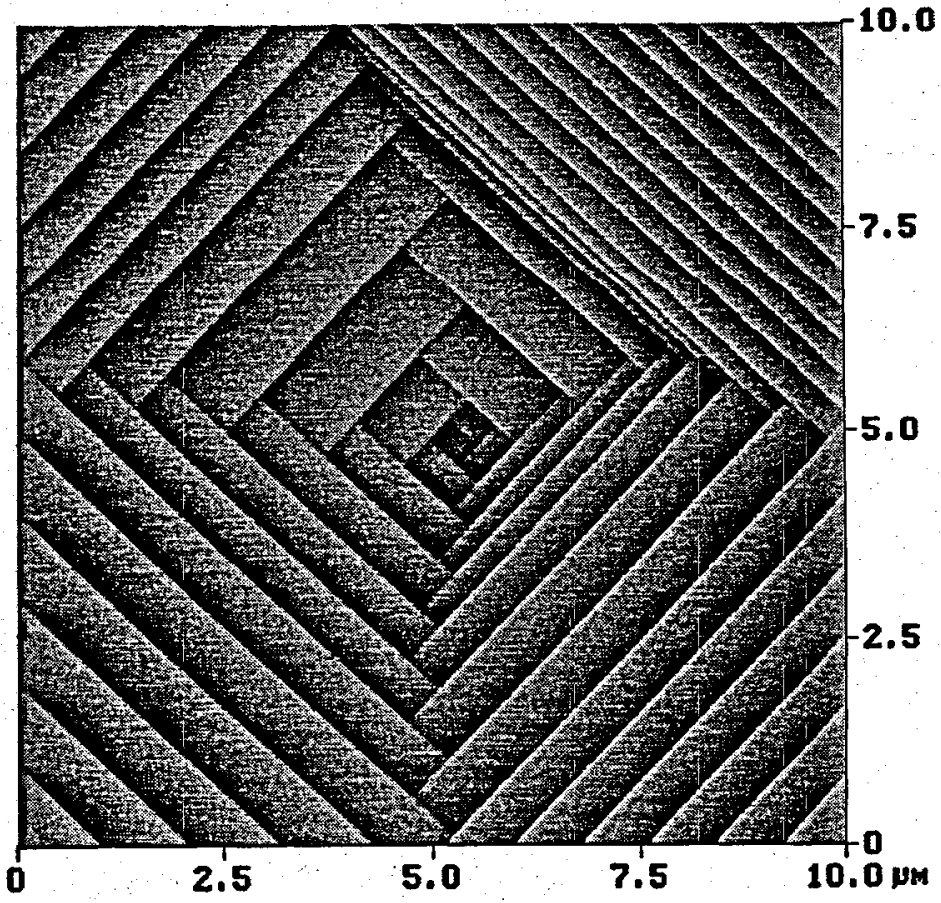




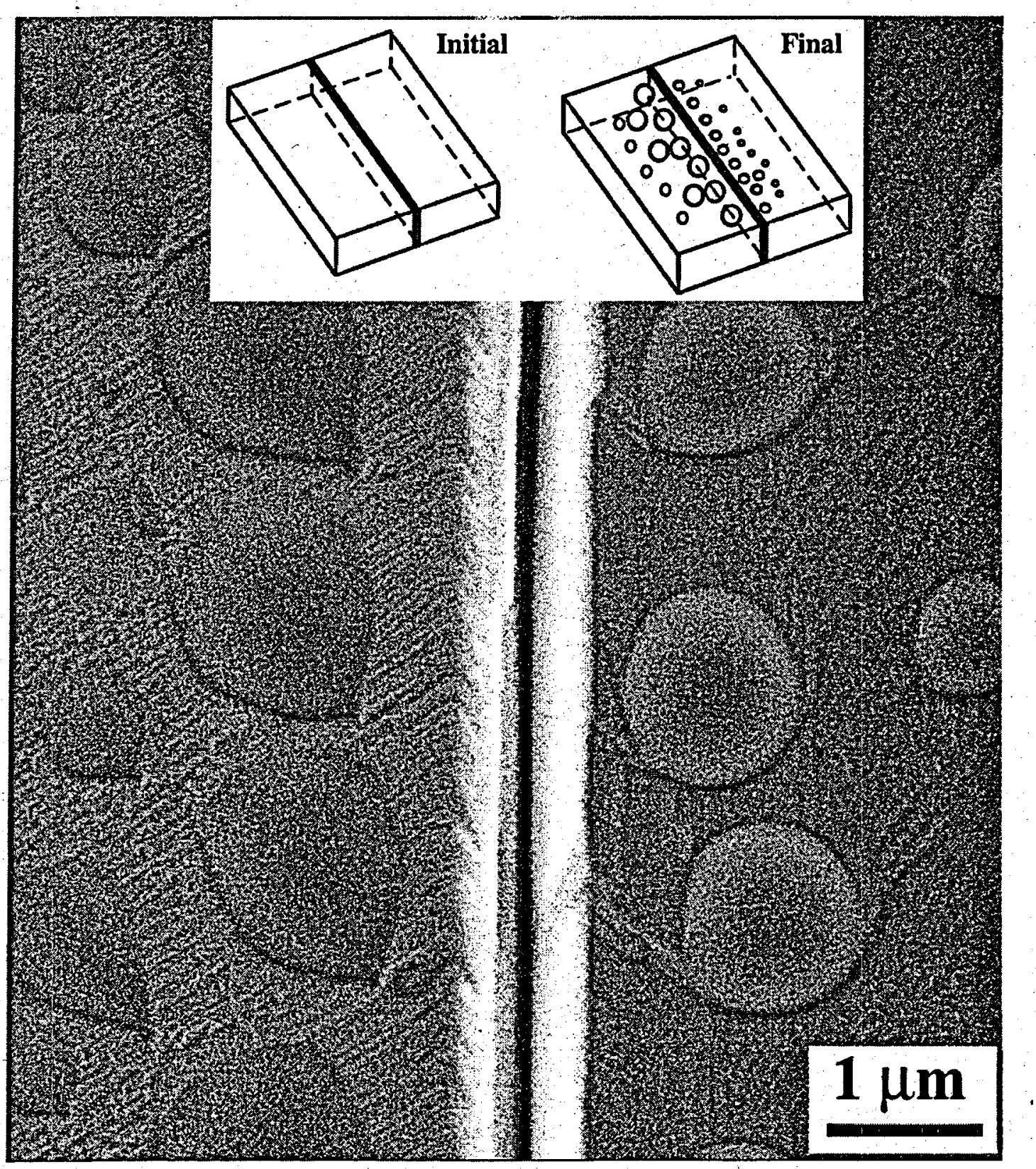

Figure 9. SE image from a cc bicrystal of $\mathrm{Al}_{2} \mathrm{O}_{3}$ annealed at $1650^{\circ} \mathrm{C}$ for $2 \mathrm{~h}$. The anorthite liquid $\left(\mathrm{CaAl}_{2} \mathrm{Si}_{2} \mathrm{O}_{8}\right)$ that was present in the boundary migrates to the free surface at the annealing temperature. The migrated liquid dewets the surface on cooling. The inset shows a schematic of the starting state of the bicrystal and the bicrystal after the annealing treatment. 


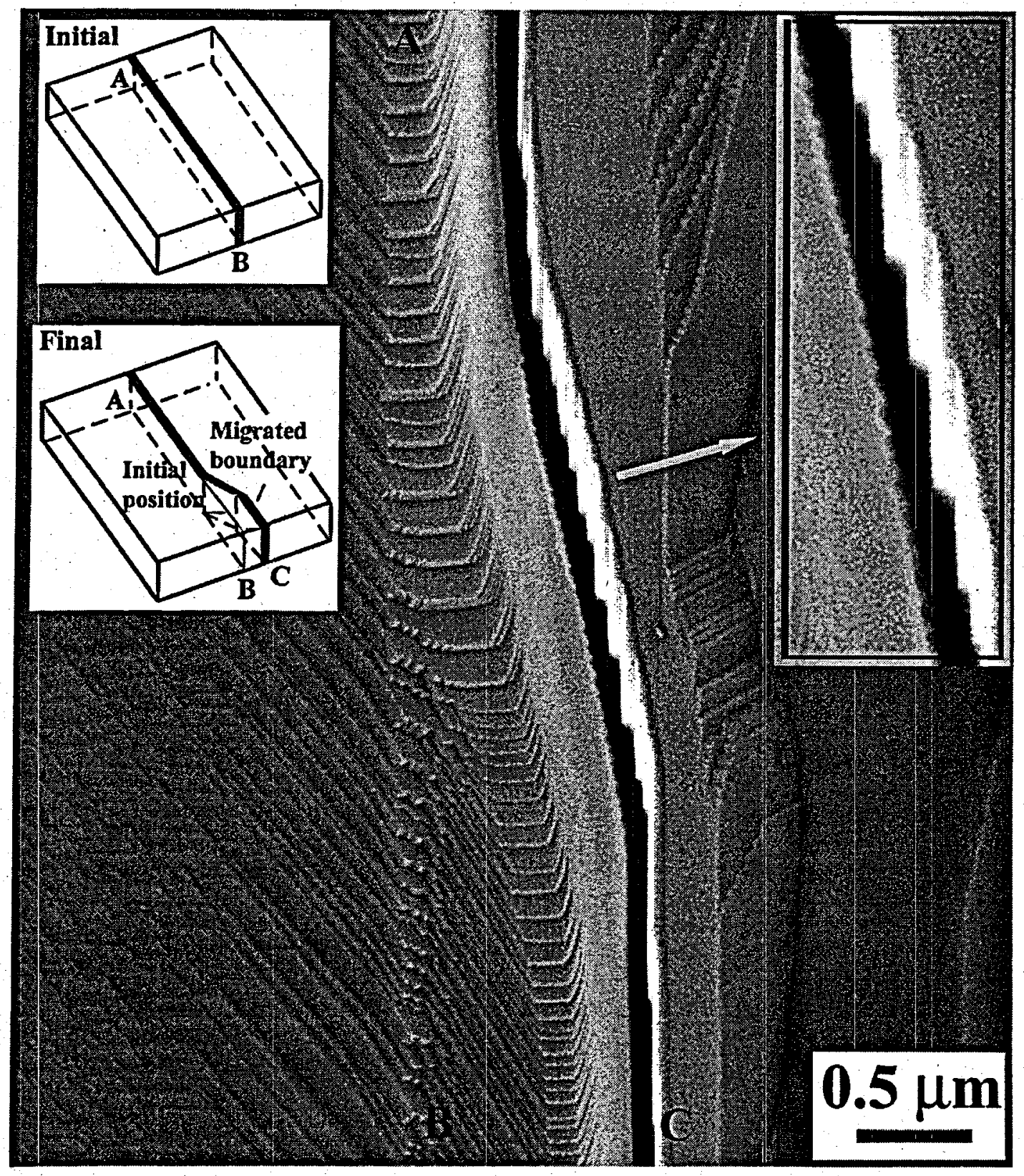

Figure 10. SE image from an me bicrystal of $\mathrm{Al}_{2} \mathrm{O}_{3}$ containing anorthite liquid that was annealed at $1650^{\circ} \mathrm{C}$ for $2 \mathrm{~h}$. The boundary which was straight (vertical) initially undergoes migration to the right. The schematic shows the initial position of the boundary and the boundary position after migration. The faceting of the interface is shown magnified in the inset to the right. The boundary presumably migrates by the motion of these facets. 


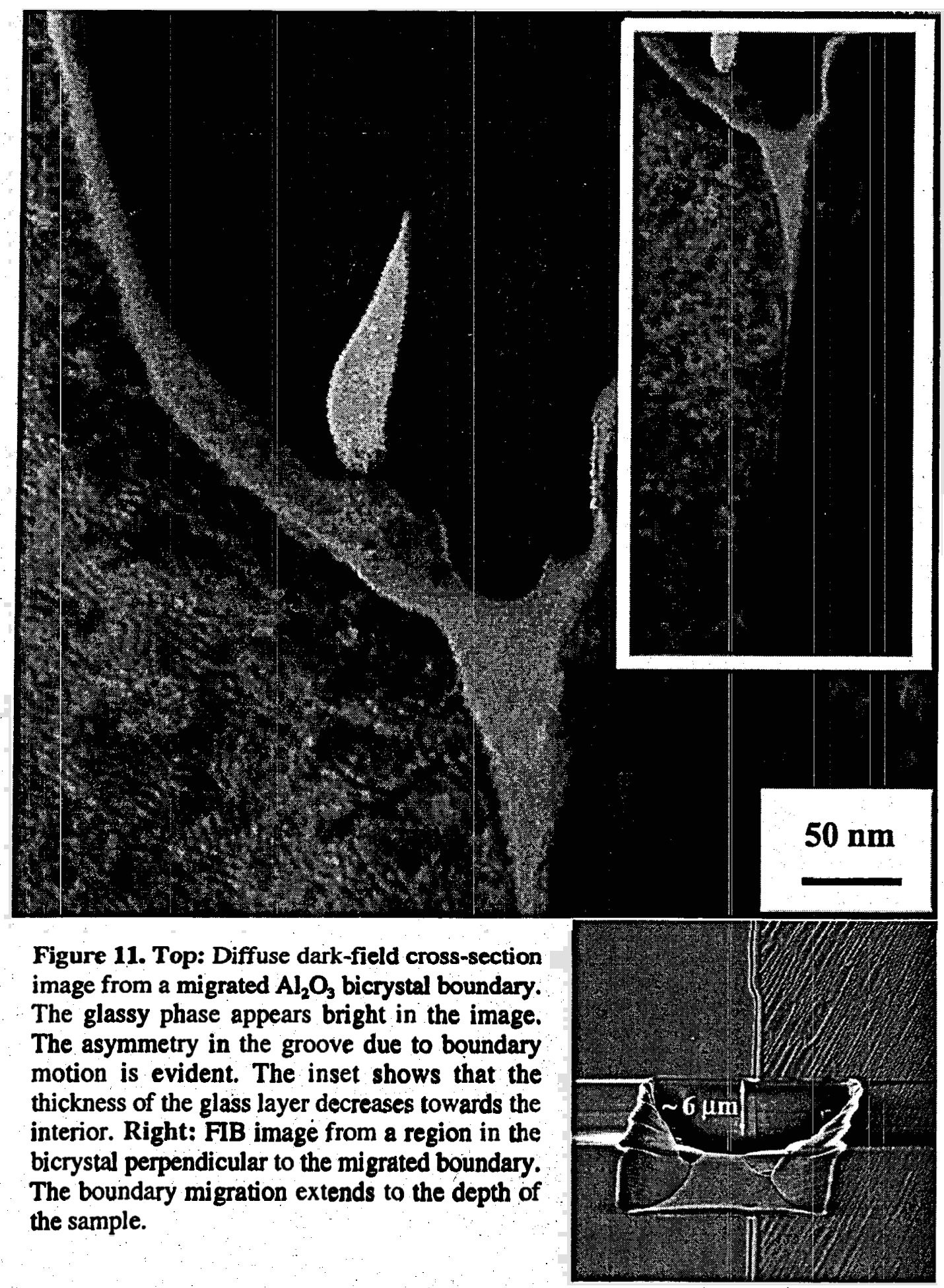




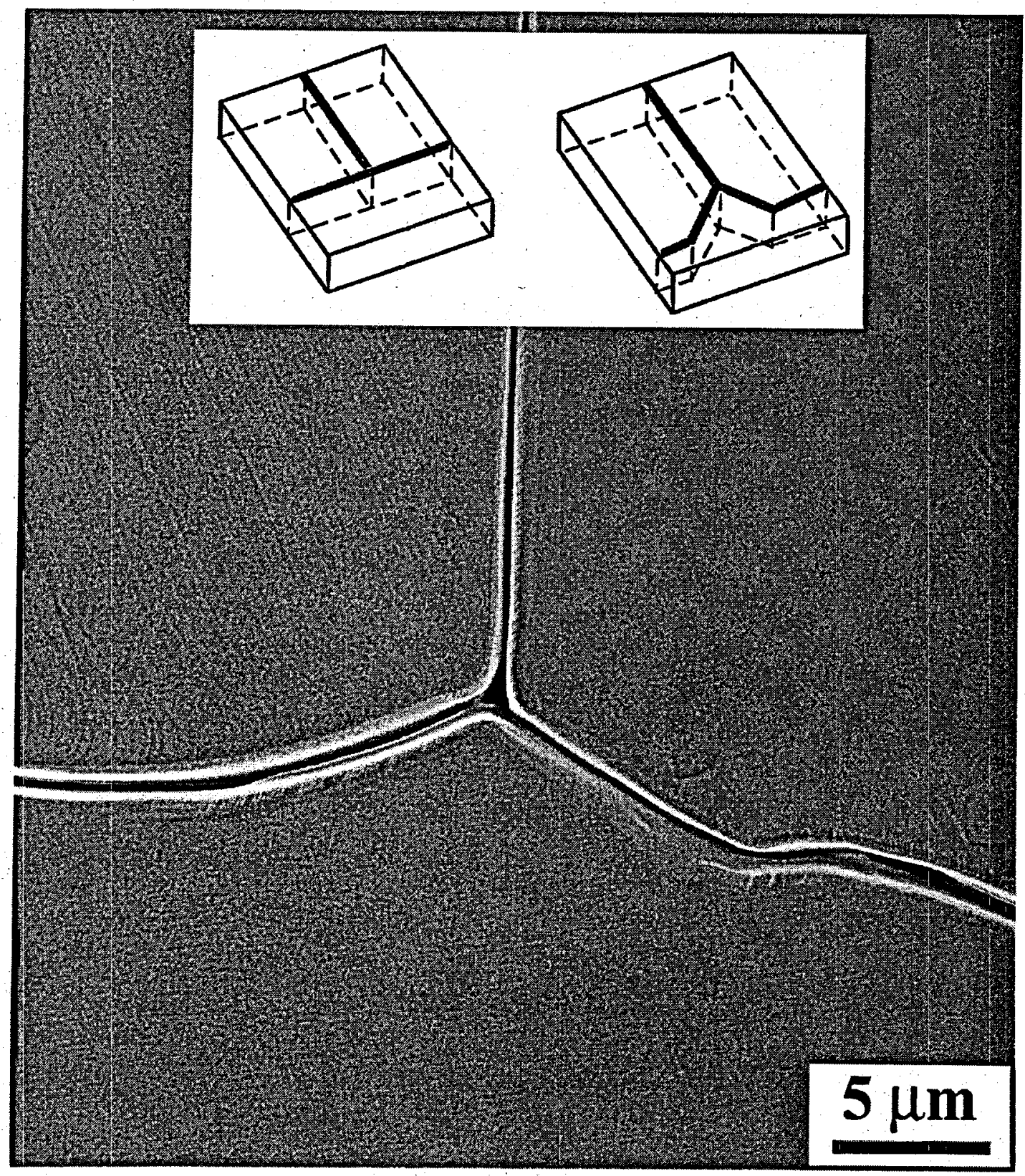

Figure 12. $\mathrm{SE}$ image of boundary migration in an $\mathrm{Al}_{2} \mathrm{O}_{3}$ tricrystal. The tricrystal, produced by bonding an mc bicrystal to c-plane of $\mathrm{Al}_{2} \mathrm{O}_{3}$ and was $\mathrm{T}$-shaped initially. The schematic represents the initial configuration and the final boundary configuration after migration. 
Figure 13. $\mathrm{SE}$ image of a grain boundary from an $\mathrm{Al}_{2} \mathrm{O}_{3}$ bicrystal. The image was taken just prior to EBSD analysis, therefore the sample has been tilted approximately $70^{\circ}$ from normal imaging position. This is the reason for the slight misfocus at the upper and lower portions of the image. The boundary in the upper half of the image has migrated about $5 \mu \mathrm{m}$ to the right. The initial position of the boundary is evidenced by the presence of the grain boundary groove at the free surface and the dark band that extends in a line from the point at which the groove starts to turn to the right, to the top of the image. The groove indicates the intersection of the grain boundary with the free surface.

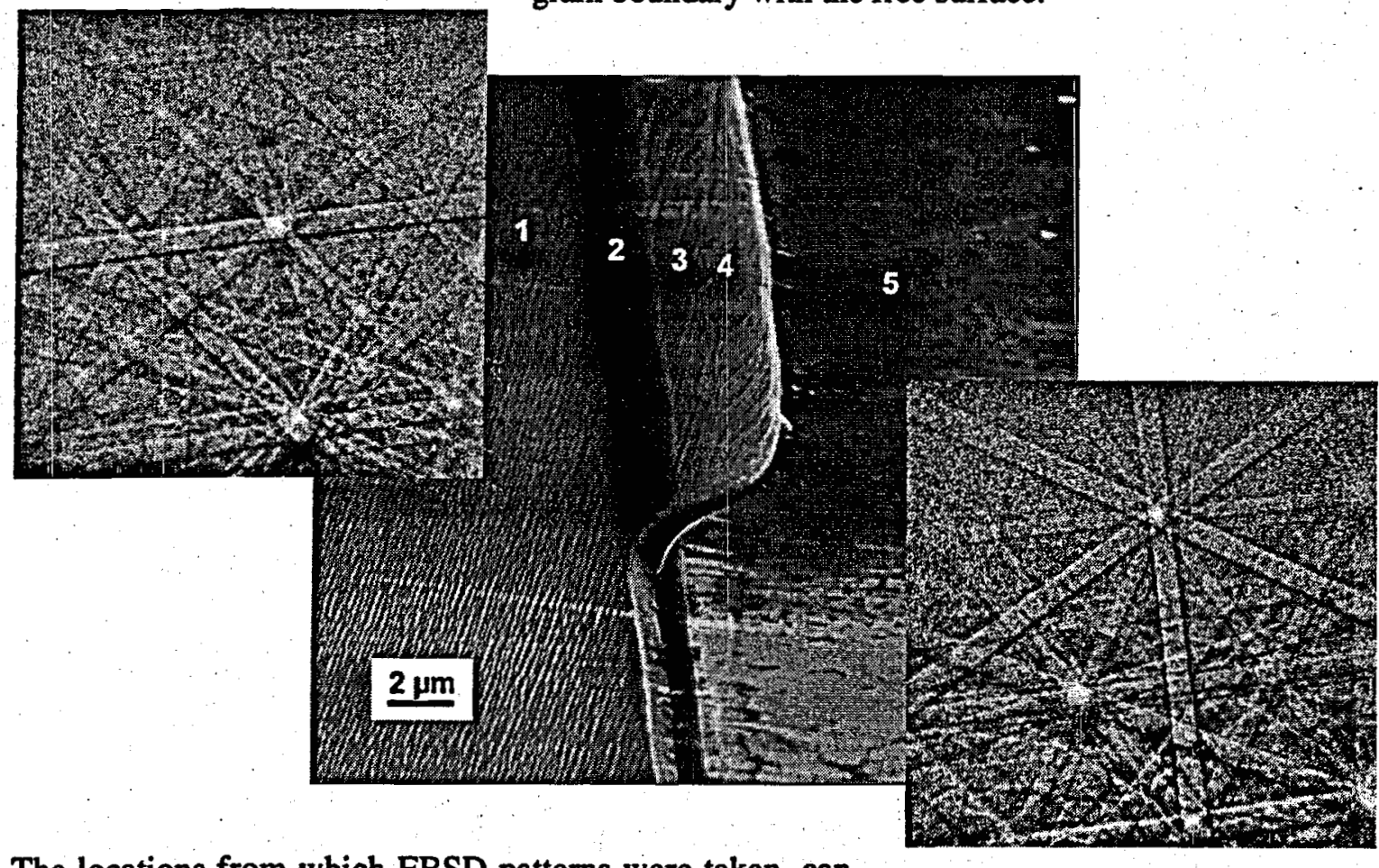

The locations from which EBSD patterns were taken, can be seen on the image as dark spots labeled 1-5. The EBSD patterns, shown as insets, were taken from locations 1 and 5 and were used to confirm the orientations of the bulk crystals on either side of the boundary. The patterns indicate that for the right side of the bicrystal, the normal to the grain boundary is [10T0] and the normal to the free surface, shown in the image, is [11 103]. The left side of the bicrystal has a grain boundary surface normal of [0001] and a free surface normal of [1 $18 \overline{7} 0]$. The patterns taken at regions 2,3 and 4 were also compared to the pattern taken from region 1 to obtain the orientation relationship of the 'regrown' portion of the crystal. 